FERNÁNDEZ-GALLARDO FERNÁNDEZ-GALLARDO, J.A., «Criterios aplicables en la acumulación de condenas», $R E D U R$ I4, diciembre 20I6, págs. 3I-65. ISSN I695-078X

\title{
CRITERIOS APLICABLES EN LA ACUMULACIÓN DE CONDENAS
}

\author{
Javier Ángel FERNÁNDEZ-GaLLARDo FERnÁNDEZ-GALLARDO \\ DOCTOR EN DERECHO \\ LETRADO DE LA ADMINISTRACIÓN DE JUSTICIA \\ JuZgAdo Central de InstruCCiÓn N² DE LA AudienCia NACIONAL
}

Sumario: I. Introducción. II. Concepto. III. Fundamento. IV. Competencia. V. Cálculo del triple de la pena más grave. VI. Conexidad. VII. Firmeza de la sentencia. VIII. Cosa Juzgada. IX. Abono de la prisión preventiva. X. Condenas dictadas por Tribunales extranjeros. X.I. Hasta la publicación de la Decisión Marco 2008/675/JAI. X.2. Publicación de la Decisión Marco 3008/675/JAI. X.3. Publicación de la LO 7/20I4. XI. Conclusiones. XII. Bibliografía.

RESUMEN: El incidente de acumulación de condenas tiene una gran importancia en todo el sistema de determinación de la pena, ya que puede alterar de manera muy sustancial las penas individualmente impuestas, estableciendo unas limitaciones con un relevante impacto en orden a la determinación del tiempo efectivo de privación de libertad a cumplir. No obstante, la complejidad y trascendencia de esta materia no se ve reflejada en su normativa reguladora, constituida por un escueto marco normativo. El presente trabajo trata de analizar los distintos aspectos sustantivos y procesales concurrentes en esta figura jurídica.

Palabras Clave: Acumulación jurídica, conexidad temporal, nueva pena, sentencia extranjera

ABSTRACT: The incident accumulation of convictions is of great importance in the whole system of sentencing, because it can change substantially the penalties individually imposed. This change can be produced by setting some limitations with a significant impact in order to determine the effective time of deprivation freedom of fulfill. However, the complexity and significance of this matter is not reflected in its regulations, consisting of a bare-bones policy framework. This paper attempts to analyze the various substantive and procedural issues concurrent in this legal concept.

KEYWORDS: Legal accumulation, temporal connectedness, new penalty, foreign judgement

\section{Introducción}

El presente trabajo gira en torno a la interpretación que deba conferirse a la forma de cumplimiento de las diversas penas impuestas al mismo sujeto, cuando todas o algunas de las penas correspondientes a las diversas infracciones cometidas no pudieran ser cumplidas simultáneamente por el condenado. 
Nuestra legislación penal parte del denominado concurso real para la extinción de todas las penas impuestas por cada uno de los delitos cometidos, bajo el principio del cumplimiento simultáneo de todas ellas si fuera posible, y cuando ello no lo fuere, opta por el principio del cumplimiento sucesivo, con ciertas correcciones. Naturalmente, como no es posible el cumplimiento simultáneo de varias penas de prisión a la vez, hemos de interpretar las reglas que contiene el Código Penal (en adelante CP) para disciplinar dicho cumplimiento sucesivo, faceta que abordaremos tanto para determinar el orden de cumplimiento que proceda, como para discernir las limitaciones que, en su caso, correspondan. Para ello hay que partir de la base de que nuestro derecho penal vigente instaura, como ya hemos apuntado, un sistema de determinación de la pena bajo el concurso real de delitos que se fundamenta en tres ideas: la acumulación aritmética de las penas de la misma especie (art. $73 \mathrm{CP}$ ), la ejecución sucesiva de las mismas por el orden de su gravedad (art. 75 CP), y la limitación del tiempo de ejecución (art. 76 CP).

Nuestra legislación orienta las penas hacia la reeducación y reinserción social (art. 25.2 Constitución Española -en adelante $\mathrm{CE}-$ ), proscribiendo expresamente los trabajos forzados. Pero esto no quiere decir que la reinserción social sea el único fin de la pena, sino que ha de armonizarse con otros principios, particularmente el de la prevención especial, que en delitos muy graves se combina también con criterios retributivos de la pena. El Tribunal Constitucional $^{\mathrm{I}}$ (en adelante TC) ha establecido que el art. 25.2 CE no contiene un derecho fundamental que permita fundamentar un recurso de amparo, sino que tal precepto contiene un mandato dirigido al Legislador y la Administración penitenciaria, y en suma, que dicho precepto «no resuelve sobre el mayor o menor ajustamiento de los posibles fines de la pena al sistema de valores CE, ni entre los posibles fines -prevención especial, retribución, reinserción, etc.-, ha optado por una concreta función de la pena». En consecuencia, la reinserción social no es el único fin de la pena y, por tanto, existen razones de prevención especial y de justicia que son también funciones legítimas de las penas. Por su parte el Tribunal Supremo ${ }^{2}$ (en adelante TS) ha mantenido que la pena tiene un doble componente, dadas sus especiales características, que son la finalidad resocializadora que toda pena comporta y la finalidad aflictiva -prevención especial-, que está inserta en las razones de política criminal que el legislador ha considerado para la inclusión del injusto en las leyes penales y que justifica su misma existencia legal. La reinserción social no es una finalidad absoluta de las penas privativas de la libertad establecida constitucionalmente, se trata de una orientación armonizable con otras finalidades de la pena y con la exigencia de justicia prevista en el art. I CE. De aquí se deriva que no cabe renunciar sin más a la prevención general, dentro de límites compatibles con el principio de proporcionalidad, ni tampoco a la prevención especial frente al propio sujeto que exterioriza una comprobada tendencia al delito.

I STC 120/2000, Pleno, de I0.05.2000 (BOE núm. I36 de 7.06.2000; MP: Julio Diego González Campos). La STC 2/I987, Sala Ia , de 2I.0I.I987 (BOE núm. 35 de Io.02.I987; MP: Miguel Rodríguez-Piñero y BravoFerrer), ya declaró que el art. 25.2 CE no limita la orientación de la pena a la reinserción, permitiendo la fundamentación de la pena en postulados retribucionistas o de prevención general.

${ }^{2}$ SSTS, Sala 2a , de 30.I0.200I (ROJ: STS 8469/200I; MP: Julián Artemio Sánchez Melgar); y 26.I0.200I (ROJ: STS 8327/200I; MP: Enrique Bacigalupo Zapater). 
Es claro también, que otro principio que preside la interpretación de esta materia, residenciado en consideraciones de política criminal, descansa en que el autor de las diversas infracciones cometidas debe cumplir todas o la mayor parte de las penas impuestas, sin que pueda igualarse, concediéndosele el mismo trato punitivo, al autor de un solo delito que al seriado criminal que tiene sobre sus espaldas un amplio historial delictivo. Esta interpretación ni la consiente el valor de justicia proclamado por la CE, ni resulta propiamente tampoco de la ley.

\section{Concepto}

Antes de entrar a analizar los criterios aplicables en esta figura jurídica conviene diferenciar la misma de la refundición de condenas, habida cuenta de su habitual confusión terminológica ${ }^{3}$, aun cuando sus diferencias son claras, existiendo una absoluta autonomía entre ambos institutos ${ }^{4}$. No obstante no faltan autores ${ }^{5}$ que utilizan indistintamente ambos términos para referirse a la aplicación de los límites máximos del art. 76 CP.

El término «acumulación» es utilizado generalmente para referirse a la fijación del límite máximo de cumplimiento efectivo, o más ampliamente, al propio sistema de determinación de la pena en caso de concurso real de delitos, circunscribiéndose en la fase de determinación e individualización de la pena. Este instituto comprende pues, tanto la «acumulación material», que hace referencia a su vertiente aritmética, es decir, el cumplimiento simultáneo o sucesivo de las penas -arts. 73 y 75 CP-, como la «acumulación jurídica», operación consistente en limitar el cumplimiento sucesivo de las penas -artículo $76 \mathrm{CP}-^{6}$. Operaciones ambas que son competencia del juez o tribunal sentenciador.

\footnotetext{
3 Así, el TS se viene refiriendo con normal habitualidad a la acumulación jurídica, tanto como proceso de acumulación como de refundición. SSTS, Sala $2^{a}$, de 30.II.20II (ROJ: STS 83II/20II; MP: Julián Artemio Sánchez Melgar); I8.02.2008 (ROJ: STS I920/2008; MP: Juan Ramón Berdugo Gómez de la Torre); y I8.07.1996 (ROJ: STS 4470/1996; MP: Joaquín Delgado García).

4 Téllez Aguilera, A., «La Ley de cumplimiento íntegro y efectivo de las penas: Una nota de urgencia«, en Diario La Ley, núm. 5837, I4.08.8.2003, pág. I6; y PeITEAdo MARISCAL, P., La ejecución jurisdiccional de las penas privativas de libertad, Edersa, 2000, págs. 23I y ss.

5 Entre otros muchos, GonzÁlez Rus, J. J., «Artículos 73 y 75 al 78», en Cobo Del Rosal (Coord), et al., Comentarios al CP, Edersa, Madrid, I999, págs. 949 ss.; Cuerda RiezU, A., «La regulación del concurso de delitos en el anteproyecto de Código Penal de i992», en Coвo Del Rosal, M. / Ruiz Vadillo, E. et al., Política criminal y reforma penal: homenaje a la memoria del profesor Dr. D. Juan del Rosal, EDERSA, Madrid, I993, págs. 303 ss.; Calderón Cerezo, A. / Choclán Montalvo, J. A., Derecho penal, Bosch, Barcelona, 200i, págs. 42i ss.; SuÁrez González, C., «Artículo 76», en Rodríguez Mourullo, G. (Dir.), Comentarios al Código Penal, Civitas, Madrid, I997, págs. 267 y ss.; MAQUEdA AbreU, M. L, «El concurso de delitos», en ZugALDíA EsPinAR, J. M (dir.), Derecho penal Parte general, Tirant lo Blanch, Valencia, 2002, págs. 892 ss.; SUÁREZ-MIRA RODRÍGUEZ, C. (coord.), Manual de Derecho penal, T. I, Thomson Civitas, Navarra, 2004, págs. 403 ss.; Muñoz Conde, F. / García Arán, M., Derecho penal Parte general, Tirant lo Blanch, Valencia, 20io, págs. 545 ss.

${ }^{6}$ Así, Muñoz Conde, F. / García Arán, M., Derecho penal..., ob. cit., págs. 545 y 546; Quintero Olivares, G., Manual de derecho penal, Parte general, Aranzadi, Navarra, 2002, págs. 753 y 753; MAQueda Abreu, M. L., «El concurso...», ob. cit., pág. 892; Conde-Pumpido Ferreiro, M., «Art. 76», en Conde-Pumpido Ferreiro, M. (dir.), Código Penal comentado: con concordancias y jurisprudencia, Bosch, Barcelona, 2004, págs. 285 SS.; MIR Puig, S., Derecho Penal, Parte General, Reppertor, Barcelona, 2006, pág. 645; SuÁREZ GonZÁlEZ, C., «Artículo 76», en Rodríguez Mourullo, G. (dir.), Comentarios al Código Penal, Civitas, Madrid, I997, pág. 267; GoNZÁLEZ Rus, J. J., «Artículos 73 y 75 al 78», ob. cit., págs. 95I ss.; entre otros. De igual modo, la jurisprudencia viene utilizando habitualmente esta terminología, distinguiendo entre acumulación material y acumulación
} 
Por otro lado, con el nombre de «refundición» se hace referencia a la institución representada por el art. I93.2 del Reglamento Penitenciario, de la que se desprende el principio de unidad de ejecución penitenciaria, que se sitúa en la fase de ejecución de la pena o penas derivadas del delito o delitos cometidos, y no en la de determinación las mismas7. La refundición consiste en la suma de todas las penas privativas de libertad que cumple el penado con el objeto de establecer una ficción de una única pena, y así poder disfrutar la libertad condicional correspondiente a dicha suma, como si se tratara de una única pena, siendo una competencia atribuida al juez de vigilancia penitenciaria ${ }^{8}$.

\section{Fundamento}

La doctrina del TS9 estima que la acumulación de condenas prevenida en el art. 988 de la Ley de Enjuiciamiento Criminal (en adelante LECRIM) tiende a hacer efectivas las previsiones del art. $76 \mathrm{CP}$ sobre tiempos máximos de cumplimiento efectivo en caso de condenas diferentes por varios delitos, que establece dos tipos de límites. Uno relativo, impuesto por discutibles razones de política criminal, limita el cumplimiento total de la condena del culpable al triplo del tiempo por el que se le impusiere la más grave de las penas en que haya incurrido, declarándose extinguidas las que procedan desde que las ya impuestas -esto es, cumplidas sucesivamente-, cubrieren el máximo de tiempo predicho. Y otros de carácter absoluto ${ }^{\mathrm{I0}}$, esta vez fundados en razones humanitarias y de proscripción de tratos o penas inhumanas o degradantes (art. $15 \mathrm{CE}$ ), previenen una duración básica máxima de 20 años de prisión, o en su caso, 25, 30 o 40 años, mediante el cumplimiento de las sucesivas penas impuestas en un mismo proceso, o tras la verificación de una operación

jurídica (SSTS, Sala 2a de 2.02.2012 (ROJ: STS 522/20I2; MP: Juan Ramón Berdugo Gómez de la Torre); I6.03.20IO (ROJ: STS II49/20Io; MP: Juan Ramón Berdugo Gómez de la Torre); 29.01.20I2 (ROJ: STS 87/2009; MP: Juan Ramón Berdugo Gómez de la Torre); y 4.07.2000 (ROJ: STS 5472/2000; MP: Juan Ramón Bergudo Gómez de la Torre).

7 FERnÁndez Pinós, J. E., «Acumulación de condenas y refundición de penas», en Estudios jurídicos, Cuerpo de Secretarios Judiciales, núm. 2, Ministerio de Justicia, Madrid, 2000, págs. 222 y 223; FernándeZ AréVAlo, L. / Nistal Burón, J., Manual de derecho penitenciario, Aranzadi, Navarra, 20iı, pág. 366; ArmentA GonZÁlez Palenzuela, F. J. / Rodríguez Ramírez, V., Reglamento penitenciario comentado: análisis sistemático y recopilación de legislación, MAD, Sevilla, 2004, pág. 333; CERVElló Donderis, V., Derecho penitenciario, Tirant lo Blanch, Valencia, 2006, pág. 25I.

8 AATS, Sala $2^{a}$, de 25.05.I990 (ROJ: ATS 2I29/1990; MP: Francisco Soto Nieto); 5.03.I990 (ROJ: ATS 287/I990; MP: Enrique Bacigalupo Zapater); y I4.Io.I989 (ROJ: ATS 756/1989; MP: José Hermenegildo Moyna Méndez). Y en el mismo sentido, la Consulta FGE 3/1989 y el informe del CGPJ de i6.02.I987.

9 SSTS, Sala 2a , de 30.I2.20I4, (ROJ: STS 5524/20I4; MP: Juan Ramón Berdugo Gómez de la Torre); I6.I2.20I4 (ROJ: STS 44I4/20I4; MP: Juan Ramón Berdugo Gómez de la Torre); 9.07.20I4 (ROJ: STS 3I28/20I4; MP: Juan Ramón Berdugo Gómez de la Torre); 24.06.20I4 (ROJ: STS 2493/20I4; MP: Juan Ramón Berdugo Gómez de la Torre); I.07.2013 (ROJ: STS 3557/2013; MP: Juan Ramón Berdugo Gómez de la Torre); y I0.03.2015 (ROJ: STS 821/2015; MP: Juan Ramón Berdugo Gómez de la Torre).

Io Respecto a la justificación para el establecimiento de estos límites extraordinarios, Ayo FernÁNDEZ, M., Manual de determinación de las penas y de las demás consecuencias jurídico-penales del delito, Aranzadi, Pamplona, I997, pág. 212, dice: «La elevación del límite está plenamente justificado en relación a ciertos delitos que socialmente se consideran realmente graves, como el asesinato». Para SERRAno ButragueÑo, I., Las penas en el nuevo C.P. L.O. Io/I995. Doctrina, Jurisprudencia, Derecho comparado y Casos prácticos, Comares, Granada, I996, pág. 202, los argumentos que se vienen utilizando para su justificación, como son el evitar los efectos criminógenos, o razones de justicia retributiva o material, «pugnan con los fines reeducadores y resocializadores de las penas privativas de libertad». 
de acumulación jurídica, como a la que seguidamente nos vamos a referir.

Estos límites son de gran relevancia pues tienen un fundamento constitucional, ya que responden a la necesidad de evitar que una excesiva prolongación de la privación de libertad pueda producir un efecto contrario a la reeducación y reinserción social prevenidas en el art. 25.2 CE como finalidad esencial a la que están orientadas las penas privativas de libertad $^{\text {II }}$. La resocialización del delincuente constituye un objetivo imprescindible en la ejecución de las penas, aunque es compatible con la prevención general y especial como finalidades perseguidas con la imposición de la pena. Tales limitaciones no son fruto de los más recientes Códigos, sino que fueron ya proclamadas por el CP de $1870^{\mathrm{I} 2}$. La doctrina histórica ya había aducido, en contra del estricto sistema de acumulación material, razones basadas, de una parte, en el desprestigio en el que podían incurrir unos órganos judiciales capaces de imponer penas superiores a la duración ordinaria de la vida humana. También se recordaba el devastador mensaje dirigido al delincuente, obligado a eliminar toda esperanza de reinserción social y, en fin, el contrasentido que implicaba la posibilidad de llegar a castigar de forma más grave una sucesión de delitos de menor entidad, frente a otros de mucha mayor eficacia lesiva. Es entendible, pues, que los sucesivos Códigos Penales de $1928^{\mathrm{I} 3}$, $1932^{\mathrm{I4}}$ y $1944^{\mathrm{IS}}$, insistieran, con uno u otro matiz, en la fijación de ciertos topes cuantitativos, también presentes en la fórmula que inspira el actual art. 76.I CP ${ }^{\mathrm{i} 6}$.

Por lo que se refiere a los límites relativos, ha de tomarse en consideración que el sistema de acumulación jurídica contenido en el art. 76 CP viene a corregir los excesos punitivos que pudieran resultar de la aplicación estricta del modelo de acumulación matemática que establece el art. $73 \mathrm{CP}$, unido al sistema de cumplimiento sucesivo establecido en el art $75 \mathrm{CP}$, debiendo resultar la suma aritmética de todas las penas superior al cómputo del triple de la más grave, pues en otro caso no se aplicaría esta limitación, al tratarse de un beneficio para el penado ${ }^{\mathrm{I} 7}$.

A diferencia de otros ordenamientos, que establecen una sola pena para diversos delitos enjuiciados en un mismo proceso, exasperando la pena del delito más grave, en el nuestro se sigue un sistema de acumulación matemática pura, que puede conducir en caso de multiplicidad de condenas a la vulneración del principio de proporcionalidad, alcanzando la suma de todas las penas legalmente correspondientes a los delitos cometidos, aun cuando fuesen delitos menores o menos graves, cantidades desorbitadas, reñidas en su cumplimiento total y sucesivo con el principio constitucional de rehabilitación de las penas, e incluso con la duración de la vida del penado. En concreto, cuando se trata de una

Ir Sobre el fundamento de la acumulación Cuerda RiEzu, A., Concurso de delitos y determinación de la pena: análisis legal, doctrinal y jurisprudencial, Tecnos, Madrid, I992, págs. 9 y ss.

I2 Art. 89.2.

13 Art. I63.I.

I4 Art. 74 .

I5 Art. 70.2.

${ }^{16}$ Más ampliamente Bérdugo Gómez De LA Torre, I. (Coord.) / De Vicente MartíneZ, R., et. al., Lecciones y materiales para el estudio del Derecho Penal, V. 2 (Teoría del delito), Iustel, Madrid, 20ıo, págs. 408 y ss.

I7 Lamo Rubio, J., Penas y Medidas de Seguridad en el nuevo Código, Bosch, Barcelona, I997, págs. 3I7 y ss. 
multiplicidad de delitos menores cometidos por el acusado en un determinado período de su juventud, en ocasiones vinculados al consumo de estupefacientes, o a otras circunstancias vitales, la regla legal establecida en el art 76 CP que limita el tiempo de cumplimiento efectivo al triple de la pena más grave, trata de evitar que quien solamente ha cometido delitos menores pueda sufrir, como consecuencia de la aplicación draconiana del sistema de acumulación matemática, una pena desproporcionada, que le mantenga en prisión durante un período tan prolongado de su vida que impida definitivamente su eventual rehabilitación. Y, al mismo tiempo, se trata de evitar que la acumulación de numerosos delitos menores acabe determinando el cumplimiento de una pena superior a la eventual comisión de delitos de mayor entidad.

Es por ello por lo que el TS ha realizado una interpretación flexible del art. $76 \mathrm{CP}$, para evitar que vicisitudes procesales diversas puedan frustrar el propósito del Legislador, provocando la superación de los límites legales y la vulneración de los principios constitucionales, en el caso de que delitos menores cometidos en una misma época de la vida del penado determinen la imposición de penas globales desproporcionadas, simplemente por haber sido enjuiciados separadamente. En este sentido el $\mathrm{TS}^{\mathrm{I} 8}$ ha manifestado reiteradamente que era necesario adoptar un criterio favorable al reo en la interpretación del requisito de conexidad que exigían los arts. 988 LECRIM y 76 CP para la acumulación jurídica de penas, estimando que para la aplicación de la refundición, más que la analogía o relación entre sí, lo relevante es la conexidad temporal, es decir que los hechos pudiesen haberse sido enjuiciado en un solo proceso, atendiendo al momento de su comisión ${ }^{19}$.

El límite absoluto, que era de veinte años efectivos en la redacción originaria del actual CP, salvo excepciones que podían alcanzar como máximo los treinta años, se ha incrementado de forma muy relevante en sucesivas reformas legislativas tendentes a alargar el máximo de cumplimiento de las penas privativas de libertad, especialmente en supuestos de terrorismo, pudiendo alcanzar en la actualidad los cuarenta años de prisión efectiva ${ }^{20}$.

${ }^{18}$ SSTS, Sala $2^{\text {a }}$, de I2.05.2004 (ROJ: STS 3236/2004; MP: Francisco Monteverde Ferrer); 30.06.2000 (ROJ: STS 5380/2000; MP: Cándido Conde-Pumpido Tourón); iG.II.I998 (ROJ: STS I4I/I998; MP: Cándido CondePumpido Tourón); I0.03.I998 (ROJ: STS I605/I998; MP: Cándido Conde-Pumpido Tourón); 20.02.I998 (ROJ: STS II54/ı998; MP: Cándido Conde-Pumpido Tourón); y 3.02.I998 (ROJ: STS 636/ı998; MP: Cándido CondePumpido Tourón), entre otras.

I9 SSTS, Sala $2^{\text {a }}$, de I9.10.2005 (ROJ: STS 627I/2005; MP: José Manuel Maza Martín); i2.09.2005 (ROJ: STS 5274/2005; MP: Carlos Granados Pérez); 21.07.2005 (ROJ: STS 507I/2005; Joaquín Giménez García); I4.07.2005 (ROJ: STS 48I2/2005; MP: José Antonio Martín Pallín); 30.06.2004 (ROJ: STS 4636/2004; MP: Joaquín Delgado García); 6.07.2000 (ROJ: STS 5580/2000; MP: Enrique Abad Fernández); 25.04.2000 (ROJ: STS 3477/2000; MP: Roberto García-Calvo Montiel); y 30.03.2000 (ROJ: STS 2575/2000; MP: José Jiménez Villarejo), entre otras muchas.

20 Así, Muñoz Conde, F, «¿Hacia un derecho penal del enemigo?», en Diario el País, Madrid, I5.oI.2003, señala «ni siquiera en las épocas más oscuras y duras de la dictadura franquista o en los años más inseguros y difíciles de la transición democrática se llegó a proponer una prolongación de la duración de la pena de prisión a 40 años», enmarcando esta medida dentro de lo que se viene denominando como «Derecho penal del enemigo». Para Renart García, F., La libertad condicional: nuevo régimen jurídico (adaptada a la LO 7/2003, de 30 de junio, de medidas para el cumplimiento íntegro y efectivo de las penas), Edisofer, Madrid, 2003, págs. I03 y ss., el aumento del límite máximo de cumplimiento de prisión a 40 años constituye «una forma encubierta de consagrar una cadena perpetua constitucionalmente inadmisible y contraria al principio resocializador que debe informar el cumplimiento de las penas privativas de libertad». En relación con la cadena perpetua ORTEGa, J., Manual de determinación de la pena: conforme al CP de I995, Tirant lo Blanch, Valencia, 
No hay que olvidar que la LO I/2OI $5^{2 \mathrm{I}}$ reintroduce en nuestro ordenamiento, bajo la denominación de prisión permanente revisable, una pena de prisión de duración indeterminada, que puede prolongarse hasta el fallecimiento del penado, y que, con carácter general, exige un mínimo de veinticinco años para acceder a la primera revisión, y en los supuestos más graves de treinta y cinco años.

En definitiva, la interpretación de los límites punitivos del art 76 CP debe hacerse, en consecuencia, en forma preordenada al efectivo cumplimiento de los diversos fines de la pena, favoreciendo la reinserción del penado en la sociedad, y evitando al mismo tiempo que puedan generarse situaciones de impunidad o actuaciones criminógenas respecto de posibles delitos futuros.

\section{Competencia}

Conforme al párrafo 3 del art. 988 LECRIM la competencia viene atribuida al «Juez o Tribunal que hubiere dictado la última sentencia». Ya la Consulta FGE de 23.02.I968 sobre aplicación del art. 988 LECRIM en relación con la regla segunda del art. 70 CP consideraba que «es el último Juez o Tribunal que dictó sentencia quien tiene que apreciar si existe relación o analogía entre los hechos motivo de las condenas impuestas en los distintos procesos para acordar cuáles debieron ser objeto de uno solo y fijar el cumplimiento de las mismas». Por tanto, la competencia para tramitar el incidente se otorga al Juez o Tribunal que hubiera dictado la última sentencia ${ }^{22}$. La jurisprudencia reciente del TS ${ }^{23}$ recuerda a estos efectos lo decidido en Acuerdo del Pleno No Jurisdiccional de la Sala $2^{a}$ TS de 27.03.I998, en la que se estableció que el Juez o Tribunal que haya dictado la última sentencia deberá, también, acordar lo que proceda respecto de la acumulación entre sí de las penas correspondientes a las restantes causas que, atendiendo a las fechas de las sentencias y de la realización de los hechos, no considere acumulables a las emanadas de la causa propia en la que dictó sentencia, conceptuada como la última del listado atribuible al reo.

I999, pág. I76, señala que algunos países de nuestro entorno cultural, social y político, como Francia, Inglaterra, Italia, Bélgica o Alemania, recogen en sus legislaciones esta pena. En sentido contrario, MAPELLI Caffarena, B. / Terradillos Basoco, J., Las consecuencias jurídicas del delito, $3^{a}$ ed., Civitas, Madrid, I996, pág. 69, señalan que en los países del norte de Europa ha desaparecido la cadena perpetua. Destaca asimismo el pronunciamiento del TC alemán mostrándose a favor del mantenimiento de la cadena perpetua por considerar que «es necesaria para reforzar la conciencia jurídica y el sentimiento de seguridad jurídica». TÉLLEZ AGUILERA, A., «La Ley de cumplimiento íntegro...», ob. cit., pág. 7, no se muestra crítico con este incremento a 40 años, haciendo hincapié en que más que la duración de la pena, es el régimen de cumplimiento y contenido de la misma.

${ }^{21}$ LO I/20I5, de 30 de marzo, por la que se modifica la LO Io/I995, de 23 de noviembre, del CP (BOE núm. 77, de 31.03.2015).

${ }^{22}$ SSTS, Sala $2^{\text {a }}$, de 28.06.20I2 (ROJ: STS 4927/20I2; MP: Francisco Monteverde Ferrer); y I6.03.20II (ROJ: STS 2I3I/20II; MP: Juan Saavedra Ruiz). AATS, Sala 2a de 3.03.20II (ATS 3402/20II; MP: Juan Saavedra Ruiz); I8.02.2010 (ROJ: ATS 3767/2010; MP: Miguel Colmenarejo Menéndez de Luarca); y I4.Io.20I0 (ATS I3960/2010; MP: Julián Artemio Sánchez Melgar).

23 SSTS, Sala $2^{a}$, de I0.07.2013 (ROJ: STS 4453/2013; MP: Juan Saavedra Ruiz); 29.05.2009 (ROJ: STS 3358/2009; MP: José Antonio Martín Pallín); y 9.I0.2006 (ROJ: STS 5928/2006; MP: José Antonio Martín Pallín), entre otras muchas. 
Por otra parte, será competente para acumular el Juez o Tribunal que hubiera dictado la última sentencia aunque una vez resuelto el incidente, excluya del auto de acumulación su propio fallo condenatorio por no ser conexo. En estos casos no deberá inhibirse al siguiente órgano sentenciador por antigüedad sino que habrá de proceder a fijar el máximo de cumplimiento ${ }^{24}$. El citado Acuerdo del Pleno No Jurisdiccional de la Sala $2^{\mathrm{a}}$ TS de 27.03.I998 establece que si el Juez o Tribunal que haya dictado la última sentencia no considera acumulables las penas correspondientes a las restantes causas a las resultantes de la propia, conserva su plena competencia para refundir entre sí las que procedan de aquéllas. Cosa distinta es la sentencia que determina la acumulación, que necesariamente ha de ser la de fecha más antigua entre todas las que se pretende acumular, con independencia del órgano que la hubiere dictado.

El órgano competente puede ser un Juzgado de lo Penal siempre que haya dictado la última sentencia condenatoria ${ }^{25}$, y ello aunque existan otras sentencias acumulables dictadas por Audiencias Provinciales. No se residenciará la competencia en la Sala $2^{a}$ TS, aunque hubiera casado la última sentencia. En tal caso conocerá la Audiencia que dictó la sentencia casada, permitiendo así el recurso de casación contra el auto que resuelva el incidente de acumulación.

Conforme al art. 80I LECRIM, en el ámbito de las diligencias urgentes del procedimiento para el enjuiciamiento rápido de delitos, puede el Juzgado de Instrucción en funciones de guardia dictar sentencia condenatoria de conformidad. Se plantea si en este supuesto será en competente el Juez de Instrucción para resolver el incidente de acumulación, cuando ha sido la suya la última sentencia dictada. Debe tenerse presente que aunque en estos casos el Juez de Instrucción dicta sentencia no es competente para ejecutarla. En efecto, el art. 80I.4 LECRIM dispone que «dictada sentencia de conformidad y practicadas las actuaciones a que se refiere el apartado 2, el Juez de guardia acordará lo procedente sobre la puesta en libertad o el ingreso en prisión del condenado y realizará los requerimientos que de ella se deriven, remitiendo el Secretario Judicial seguidamente las actuaciones junto con la sentencia redactada al Juzgado de lo Penal que corresponda, que continuará su ejecución». Parece claro que la voluntas legis es restringir las competencias de ejecución del Juez de Instrucción y otorgarlas aún en estos casos con plenitud al Juzgado

24 SSTS, Sala $2^{\circ}$, de I4.05.20I4 (ROJ: STS 2338/20I4; MP: Andrés Palomo del Arco); 24.02.20I2 (ROJ: STS III9/20I2; MP: Cándido Conde-Pumpido Tourón); 5.07.2006 (ROJ: STS 425I/2006; MP: Diego Antonio Ramos Gancedo); y I0.I2.2004 (ROJ: STS 80I8/2004; MP: Miguel Colmenero Menéndez de Luarca).

25 STS, Sala 2a , de I8.05.I995 (ROJ: STS 28I8/1995; MP: Cándido Conde-Pumpido Tourón). Se muestran críticos con esta fórmula y entienden que sería mejor escoger el de mayor categoría, dejando el criterio

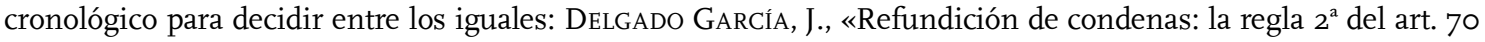
CP», en La Ley, núm. 4, I995, pág. II84; LóPEZ CERRADA, V. M., «La acumulación jurídica de penas», en Revista de Estudios Penitenciarios, núm. 250, 2004, pág. 55, entendiendo que, que al atribuir la competencia al órgano judicial de mayor categoría se solucionarían las reticencias respecto al pronunciamiento sobre sentencias y formas de cumplimiento de sentencias impuestas por órganos superiores, y por otra parte simplificaría el procedimiento; y MANZANo Moreno, E. C., La ejecución penal: estudio crítico legal y jurisprudencial sobre una materia relegada, Dykinson, Madrid, 20I2, pág. 85, que sugiere una reforma procesal que distinguiera a estos efectos entre penas acumulables impuestas en una sola sentencia o en distintos procesos y que en el primer caso atribuyese la competencia a ese mismo juez o tribunal sentenciador, mientras que en el segundo fuese atribuida, no a un órgano sentenciador sino al Juez de Vigilancia Penitenciaria de la jurisdicción de la que dependa el centro penitenciario en que se encontrase el penado. 
de lo Penal. Teniendo en cuenta que el incidente de acumulación entra de lleno en el núcleo de la fase de ejecución, y partiendo de que lo que en él se resuelve tendrá un relevante impacto en orden a la determinación del tiempo efectivo de privación de libertad a cumplir, habrá de entenderse que el Juzgado competente para acumular en estos casos será, no el Juzgado de Instrucción sino el Juzgado de lo Penal que resulte competente para la ejecución de la sentencia dictada por aquél ${ }^{26}$.

\section{Cálculo del triple de la pena más grave}

En lo que se refiere al cálculo del triple de la pena más grave de todas las que se consideran acumulables, relevante para fijar el límite máximo de cumplimiento, ha de tenerse en cuenta que, como señala el $\mathrm{TS}^{27}$, han de tomarse en consideración las penas individuales y no la totalidad de las impuestas en una misma causa ${ }^{28}$. Se habla de pena en singular, y por consiguiente, si en una o en varias sentencias figuras distintas penas, se realizará un tratamiento individualizado de cada una de ellas ${ }^{29}$. Para poder establecer el límite del triple de la pena más grave, primero hay que determinar cuál es la pena más grave. La gravedad de las penas no viene dada por su duración, sino por su naturaleza ${ }^{30}$. Esto es, son más graves las penas privativas de libertad que las privativas de derechos. En consecuencia, concurriendo penas privativas de libertad y penas privativas de derechos, se tomará la pena de mayor duración de entre las primeras. En el supuesto de que alguna de las penas tuviera aplicado un indulto parcial, se plantea el problema de determinar si la cuantía a tener en cuenta es de la pena impuesta en sentencia, o la pena reducida por el indulto ${ }^{31}$. Al efecto hemos de significar que el indulto no crea una nueva pena, sino que declara exento de cumplimiento una parte de la misma, en consecuencia la pena impuesta sigue siendo la inicial, por lo que deberá ser esta, la que se tome en cuenta a efectos de determinación de la más grave ${ }^{32}$.

${ }^{26}$ AAP Álava, Sec. 2a de I9.05.2010 (ROJ: AAP VI I33/2010; MP: Jesús María Medrano Durán).

${ }_{27}$ STS, Sala 2a , de 7.II.20I4 (ROJ: STS 4460/20I4; MP: Ana María Ferrer García).

${ }_{28}$ Este error se comete con frecuencia, al realizar el cuadro de las fechas de los hechos, fechas de las sentencias, que a partir del or.07.20I5 tendrán que incluir las fechas de enjuiciamiento, y penas impuestas, pues en ocasiones se suman las impuestas en cada causa, sin tomar en consideración que para determinar el límite del triple de la más grave, la relevante es la más alta de las penas impuestas en concreto, y no la totalidad de la pena impuesta en una sola causa.

29 LLorCa Ortega, J., Manual..., ob. cit., pág. I84.

30 STS, Sala 2a , de 15.04.1987 (ROJ: STS Io674/1987; MP: Martín Jesús Rodríguez López).

3i Para Conde-Pumpido Ferreiro, C., en López Barja De Quiroga, J. (Coord.) / Rodríguez Ramos, L. / Álvarez García, J., et al., Código Penal Comentado, Akal, Madrid, I990, pág. 206, a pesar de que la STS de 23.II.I968 establece que se deberá tener en cuenta la pena una vez reducida por el indulto, entiende que esta solución «es de legalidad más que dudosa», basa esta afirmación en el antiguo art. 69, en el que se establecía que las penas se impondrán en toda su integridad. El argumento sería perfectamente válido ahora, pues la literalidad del art. 69 coincide con el actual 73.

32 Cabe interpretar esta solución de la argumentación que utiliza MARTínez DE LA Concha Álvarez Delvayo, VIII Reunión de Jueces de Vigilancia Penitenciaria, CGPJ, Madrid, I996, págs. I3I y ss., en relación con los efectos de la acumulación, señala que el periodo de indulto, aplicado a una de las penas acumuladas, no se debe detraer en su totalidad, del límite resultante de la aplicación del art. 70 CP 73, por ser atentatorio al principio de proporcionalidad. También recoge la Circular de la Fiscalía del TS de I993, que establece el 
El triplo ha de fijarse separadamente, sin convertir en años -365 días-, los meses -30 días-, de prisión. De ese modo, por ilustrarlo con un ejemplo, el triplo de la pena de 3 años y 6 meses de prisión no será de io años y 6 meses, sino de 9 años y i 8 meses, que a efectos de cómputo no es exactamente lo mismo. Los meses han de computarse a estos efectos como de 30 días y los años como de 365 días. No es posible, a través de la operación aritmética de búsqueda del triplo de la más grave, convertir doce meses en doce meses y cinco días ${ }^{33}$.

Para determinar los límites máximos de cumplimiento establecidos en las letras a) a d) del art. 76.I CP hay que atender a la pena máxima imponible pero teniendo en cuenta las degradaciones obligatorias en virtud del grado de ejecución del delito ${ }^{34}$. Es decir, que cuando el art. 76.I a) CP establece que la pena máxima imponible es la de 25 años, si el sujeto ha sido condenado por dos o más delitos y alguno de ellos esté castigado por la ley con pena de prisión de hasta 20 años, al ser el delito intentado una categoría propia y distinta del consumado, la pena abstracta en este caso es toda la que permite la aplicación de la pena inferior en grado, considerada en toda su extensión, y será ese marco penal derivado del grado de ejecución el que debe cumplir los requisitos de «hasta 20 años» 0 «más de 20 años». Si estudiado el expediente acumulador resultan acumulables unas penas y excluidas otras, se fijará el límite máximo de cumplimiento de las acumulables, si es que ello beneficia al reo, y subsistirán con su extensión dosimétrica previa las que no lo sean.

Si el órgano judicial advierte que no todas las penas son acumulables entre sí, pero que sí lo son por bloques, deberá fijar los límites máximos de cumplimiento de cada uno de los grupos refundidos. En consecuencia, en el supuesto de que todas o algunas de las sentencias pendientes de cumplimiento no sean acumulables, será necesario proceder a la formación de sucesivos bloques penológicos. En su caso, el segundo bloque se formará partiendo de la siguiente sentencia de mayor antigüedad -excluidas, claro está, las acumuladas en el bloque anterior-, procediéndose de la misma manera antes señalada, y así sucesivamente ${ }^{35}$.

En relación a la aplicación del límite máximo de 20 años establecido en el art. 76.I $\mathrm{CP}$, el mismo opera naturalmente solo respecto de las penas ya acumuladas, de forma que las posteriores que no han podido ser objeto de acumulación por lo señalado anteriormente están sujetas a un nuevo límite conforme al precepto señalado, pues de lo contrario existiría lo que se ha denominado «patrimonio delictivo» ${ }^{6}$, que proveería al condenado de inmunidad o de una relevante reducción de penalidad para los delitos futuros, es decir, los que pueda cometer después del cumplimiento de su condena o durante la misma tanto en el caso de quebrantamiento como de delitos ejecutados durante los permisos o en el interior

«cómputo sobre el total de las penas individuales impuesta de las detracciones que sobre aquellas fueren procedentes por causas legales ajenas al tratamiento penitenciario, tales como las derivadas del indulto o modificaciones de las normas penales aplicadas».

33 STS, Sala 2a de I8.12.20I3 (ROJ: STS 5910/2013; MP: Antonio del Moral García).

34 Acuerdo del Pleno No Jurisdiccional de la Sala $2^{\text {a }}$ TS de I9.I2.20I2.

35 STS, Sala $2^{\mathrm{a}}$, de 13.02.2013 (ROJ: STS 652/2013; MP: Juan Saavedra Ruiz).

${ }^{36}$ ATS, Sala $2^{\text {a }}$, de 21.03.20I3 (ROJ: ATS 288I/2013; MP: Juan Saavedra Ruiz). 
de la prisión ${ }^{37}$. Por tanto, cada bloque mantiene su propia autonomía y sustantividad, aplicándose los límites del art. 76 CP en relación con cada uno de ellos ${ }^{38}$.

\section{Conexidad}

Para aplicar las limitaciones expuestas en el cumplimiento sucesivo de las penas, y que dará lugar a la condena total resultante, se ha de operar con un criterio de conexidad, establecido en el apartado segundo del art. 76 CP. Esa conexión puede ser de diversas clases.

En primer lugar, la llamada conexión procesal, que obliga a interpretar la misma de conformidad con la regla $5^{\text {a }}$ del art. I7 LECRIM, es decir, fundada en la analogía o relación entre los diversos delitos que se imputen a una persona que no hubieren sido hasta entonces sentenciados. Hasta la Ley $3 / 1967^{39}$, de la que traen causa los actuales arts. $76 \mathrm{CP}$ y 988 LECRIM, únicamente era posible aplicar las limitaciones en el cumplimiento de las penas para las condenas por diversos delitos que hubieran sido juzgados en un mismo proceso. La reforma que opera dicha Ley permite, por el contrario, introducir los límites para condenas recaídas en procedimientos distintos exigiendo para proceder a la acumulación de condenas la conexidad procesal. Conforme a esta interpretación la doctrina jurisprudencial impuso, en un primer momento, unas condiciones muy restrictivas para admitir la posibilidad de acumular penas privativas de libertad impuestas en distintos procesos. La jurisprudencia del $\mathrm{TS}^{40}$ utilizó la mera acumulación matemática con interpretación restrictiva de la conexidad desde el punto de vista procesal exigiendo como pautas para apreciar o no la conexidad, el tiempo, el lugar, el bien jurídico protegido, los preceptos infringidos, el modus operandi, etc., que en más de una ocasión dieron lugar a grandes arbitrariedades en la apreciación de la referida conexidad ${ }^{4 \mathrm{I}}$.

En segundo lugar, una conexión material, que responde a exclusivos criterios de acumulación de delitos, a modo de concurso real, sin fijarse en la índole o entidad de tales infracciones ${ }^{42}$. Este criterio, bajo los principios de racionalidad, de cumplimiento del mandato constitucional del art. 25.2 CE, de orientación resocializadora del sistema

37 SSTS, Sala $2^{\mathrm{a}}$, de 15.09.2005 (ROJ: STS 529I/2005; MP: Juan Ramón Berdugo Gómez de la Torre); y 9.06.2004 (ROJ: STS 3966/2004; MP: Francisco Monteverde Ferrer).

$3^{8}$ SSTS, Sala $2^{a}$, de 23.05.2006 (ROJ: STS 3137/2006; MP: Juan Ramón Berdugo Gómez de la Torre); y I6.06.2005 (ROJ: STS 3946/2005; MP: Joaquín Delgado García).

39 Ley 3/1967, de 8 de abril, sobre modificación de determinados artículos del CP y de LECRIM (BOE núm. 86, de II.04.1967).

40 STS, Sala 2a de 6.II.I992 (ROJ: STS 8254/I992; MP: Carlos Granados Pérez).

4I Conforme resume Nistal BuRón, J., «La interpretación jurisprudencial de la «conexidad» en el concurso real de delitos (art. 76.2 del CP). El sentido de la pena y la Ley penitenciaria como criterio de apreciación», en Revista de Derecho Penal, núm. 29, 20I0, págs. I08, el criterio procesal requería para apreciar la conexidad los siguientes requisitos: la unidad subjetiva, esto es, que se trate de los mismos partícipes; la unidad objetiva, es decir, delitos de la misma índole, y cierta unidad espacio-temporal que hubiera permitido esa acumulación procesal en una misma causa, aunque de hecho hayan sido varias.

$4^{2}$ Este criterio se comienza aplicar a raíz de la STS, Sala 2a de 30.05.I992 (ROJ: STS 4323/I992; MP: Enrique Ruiz Vadillo). 
penológico, de proporcionalidad, de favorecimiento al reo y de concepción del Derecho como orientado a la justicia, como suma de equilibrios, introduce la posibilidad de realizar una interpretación extensiva y analógica del concepto de conexidad de la acumulación de condenas más allá de las matemáticas y de la idea misma de conexidad.43. En este sentido la jurisprudencia del TS44 entendió que la aparente antinomia que en el examen de la conexidad se produce entre los art. 988 de la Ley procesal y art. 76 CP (art. 73 CP I973) se resuelve en favor de la aplicación de la norma penal por razones tanto formales como materiales. La conexidad exigible en el art. 76 del texto punitivo y en el art. 988 de la Ley procesal no es la objetiva basada en la analogía o relación esencial entre los hechos delictivos a que se refiere la regla $5^{\text {a }}$ del art. I7 LECRIM, sino la temporal, entendiéndose que solo podrán acumularse las penas impuestas por hechos delictivos que hubiesen podido ser enjuiciados en un mismo proceso. Es decir, el art. 988 LECRIM establece que la conexidad se ha de juzgar de acuerdo con el art. I7 del mismo texto legal, siendo así que este último precepto se refiere a la conexidad para la competencia de la jurisdicción ordinaria en supuestos de competencia territorial, mientras que el art. $76 \mathrm{CP}$ se ocupa de la conexidad a efectos del concurso real de delitos, y es este último el que debe prevalecer por $\mathrm{su}$ propia especificidad, y porque de lo que se trata es de aplicar el concurso real de infracciones penales a hechos juzgados en diferentes procesos. Conforme a esta jurisprudencia pueden ser objeto de acumulación jurídica todas las condenas por delitos que pudieran haber sido enjuiciados conjuntamente, con independencia del bien jurídico protegido por los distintos hechos e independientemente de los criterios de conexión del art. I7 de la Ley procesal.

Y finalmente, la conexidad temporal ${ }^{45}$, que atiende tan solo a un criterio estrictamente cronológico, es decir, tan solo referido al dato esencial de que, en definitiva, los delitos hubieren podido ser realmente enjuiciados en un mismo procedimiento, a la vista de las diferentes fechas de acaecimiento y posterior enjuiciamiento de los mismos ${ }^{46}$. Conforme a este criterio cronológico para el cálculo de la procedencia o no de una acumulación entre varias condenas, se tienen que tener muy en cuenta las fechas de la comisión de los hechos para ponerlos en conexión con las fechas de las sentencias de las distintas causas y, a partir de ahí, calcular qué causas se pueden incluir en un grupo de

43 Constatando que el art. 76.2 CP no exige ninguna clase de homogeneidad entre los diferentes delitos, la STS, Sala 2a , de 3.II.I995 (ROJ: STS 5498/I995; MP: José Manuel Martínez-Pereda Rodríguez), declara que para apreciar la conexidad «solo debe atenderse a si los delitos han podido ser enjuiciados en un solo proceso y ello existirá siempre que la acumulación no transforme en una exclusión de la punibilidad para todo delito posterior al último que se acumula». En igual sentido, SSTS, Sala 2a , de I5.II.I996 (ROJ: STS 6380/1996; MP: Manuel Areal Álvarez); I5.09.I997 (ROJ: STS 6380/1996; MP: José Manuel Martínez-Pereda Rodríguez); y I3.05.I999 (ROJ: STS 3308/I999; MP: Manuel Areal Álvarez).

44 SSTS, Sala 2a de 4.02.2000 (ROJ: STS 754/2000; MP: Andrés Martínez Arrieta); 20.04.I999 (ROJ: STS 26I2/I999: MP: Andrés Martínez Arrieta); I6.or.I998 (ROJ: STS I4I/I998; MP: Cándido Conde-Pumpido Tourón); y I7.IO.I997 (ROJ: STS 6I64/I997; MP: Cándido Conde-Pumpido Tourón).

45 SSTS, Sala 2a de 30.10.2013 (ROJ: STS 5265/20I3; MP: José Manuel Maza Martín); y 28.oI.20II (ROJ: STS 388/20II; MP: José Manuel Maza Martín).

$4^{6}$ Se trata sencillamente, como señala FERRER GuTIÉRreZ, A., Manual práctico sobre ejecución penal y derecho penitenciario, Tirant lo Blach, Valencia, 20II, pág. 23, de un juego de fechas, para el que será completamente intranscendente la naturaleza de los hechos o delitos a considerar. 
condenas y cuáles no47.

La actual doctrina del $\mathrm{TS}^{48}$ se viene manifestando en una doble dirección. En primer lugar, con un criterio amplio en cuanto a la clase de los delitos a acumular -ratione materiae-, interpretando la conexión desde perspectivas sustantivas, alejadas del criterio de la conexión procesal de los arts. I7 y 300 LECRIM, de tal forma que, en consideración a las razones humanitarias que constituyen el fundamento de estas normas, la clase concreta de delito cometido no ha de ser obstáculo que pueda impedir su aplicación. Este criterio amplio en beneficio del reo permite la acumulación de todas las condenas que, por la época en que ocurrieron los hechos delictivos, pudieron haber sido objeto de un único procedimiento. Si no lo fueron por razones de índole territorial, o por la diferente clase de infracciones cometidas, o por haber sido tramitados unos procesos con rapidez y otros con lentitud, o por cualquier otra razón, si se trata de hechos de una misma época, cualquiera que fuese la razón procesal por la que no todos fueron enjuiciados en una misma causa, cabrá acumular la totalidad de las penas impuestas a los efectos de aplicar esos límites máximos impuestos por las referidas normas sustantivas, en consideración a unos criterios humanitarios, ajenos a los avatares procesales concretos de cada procedimiento.

En segundo lugar, con un criterio estricto en cuanto a la otra exigencia expresamente requerida en el CP. Que los diferentes procesos, en los que esas diversas condenas a acumular se impusieron, «pudieran haberse enjuiciado en uno solo»-ratione temporis-. Cuando hay una sentencia condenatoria es claro que los hechos delictivos cometidos con posterioridad a tal sentencia no pudieron ser objeto de aquel otro proceso anterior en que ya esta había sido dictada. El TS49 viene fundando esta limitación en la peligrosidad que existiría, como facilitadora de la comisión de nuevos delitos, cuando un condenado, por las penas que ya tiene impuestas, sabe que puede cometer algún delito porque la pena correspondiente a esta nueva infracción no tendría que cumplirla al haberse ya superado, con las condenas anteriores, los límites legalmente establecidos. Evidentemente no puede favorecerse el sentimiento de impunidad que habría de seguir a ese conocimiento y para ello es imprescindible ser exigente en cuanto al cumplimiento de este requisito de carácter temporal. Solo cabe acumular entre sí aquellas condenas penales relativas a hechos de una misma época, entendiendo épocas diferentes aquellas que se

47 Nistal BuRón, J., «La interpretación jurisprudencial de la conexidad en el concurso real de delitos (art. 76.2 del CP). El sentido de la pena y la Ley penitenciaria como criterio de apreciación», en Revista de Derecho Penal, núm. 29, 20I0, págs. II7 y ss., señala que el estricto criterio cronológico en el que se basa la conexidad, para hacer posible la acumulación jurídica de condenas, genera un agravio comparativo entre la situación de aquellos reclusos a los que, estando condenados a miles de años, la temporalidad de sus delitos les permite beneficiarse de la limitación establecida en el artículo 76.2 CP, frente a quienes, y a pesar de tener un menor número de años de condena, la fecha de la comisión de sus hechos delictivos los deja fuera del acortamiento de las condenas que permite la acumulación jurídica. Todo ello por una simple cuestión de las fechas en las que se juzguen los distintos hechos, lo que muchas veces depende tan solo de la mayor o menor celeridad en la tramitación de los procesos penales.

$4^{8}$ SSTS, Sala 2a , de 30.09.20I3 (ROJ: STS 4773/2013; MP: Cándido Conde-Pumpido Tourón); y 9.03.200I (ROJ: STS I896/200I; MP: Joaquín Delgado García).

49 SSTS, Sala $2^{a}$, I8.02.2008, cit.; I5.09.2000 (ROJ: STS 6458/2000; MP: Joaquín Delgado García); 29.06.2000 (ROJ: STS 53I7/2000; MP: Joaquín Delgado García); y 4.02.2000 (ROJ: STS 752/2000; MP: Joaquín Delgado García). 
encuentran separadas por la existencia de alguna sentencia condenatoria.

Hace tiempo que el $\mathrm{TS}^{50}$ se decanta por un sentido hermenéutico de la llamada acumulación de condenas, que responda a las reglas del concurso real, y es por ello, por lo que la jurisprudencia ha interpretado con mucha amplitud y flexibilidad el mencionado requisito de la conexidad, de modo que todos los delitos que sean imputados a una persona pueden ser, o podrían haber sido, objeto de enjuiciamiento conjunto, abriendo la vía de la acumulación jurídica, con el efecto de la aplicación de tales limitaciones. Únicamente se excluyen aquellos hechos delictivos que pretendan acumularse a otros que ya hayan sido objeto de enjuiciamiento, existiendo, por consiguiente, una previa sentencia firme. Este criterio cronológico es firme y rigurosamente exigido por la jurisprudencia, de modo que los hechos posteriores cometidos tras una sentencia condenatoria no pueden ser, de modo alguno, objeto de acumulación a otros ya enjuiciados. Se fundamenta tan estricto criterio en razones legales -pues procesalmente nunca podrían haber sido juzgados en un proceso anterior, cerrado por la previa constitución de una relación litigiosa, que ha devenido en el dictado de una sentencia-, y en razones de política criminal, ya que en otro caso se crearía una verdadera patente impunidad.

Este último criterio fue asumido legislativamente en la $\mathrm{LO} 7 / 2003^{5 \mathrm{I}}$, al referirse expresamente el apartado $2^{\circ}$ del art. $76 \mathrm{CP}$ reformado a la posibilidad de aplicar la limitación a hechos que no fueren conexos pero sí susceptibles de haberse enjuiciado en un mismo proceso atendiendo al momento de su comisión. En la reforma operada por la LO I/201 $5^{52}$ se abandona definitivamente la exigencia de conexión entre los hechos delictivos para la aplicación de los límites previstos en el art. 76 CP. El nuevo texto establece que «la limitación se aplicará aunque las penas se hayan impuesto en distintos procesos cuando lo hayan sido por hechos cometidos antes de la fecha en que fueron enjuiciados los que, siendo objeto de acumulación, lo hubieran sido en primer lugar». Este precepto ha de interpretarse en el sentido de que la acumulación deberá realizarse partiendo de la sentencia más antigua, pues al contenerse en ella los hechos enjuiciados en primer lugar, servirá de referencia respecto de los demás hechos enjuiciados en las demás sentencias. A esa condena se acumularán todas las posteriores relativas a hechos cometidos antes de esa primera sentencia. La redacción del precepto no impide que se examinen con el mismo criterio las demás sentencias que pudieran resultar no acumulables a esa primera, partiendo nuevamente de la más antigua de las restantes, procediendo así a conformar nuevos bloques de acumulación. Procediendo en la misma forma en lo sucesivo, si fuere posible 53 .

Parece lógico, igualmente, que las condenas cuya acumulación proceda respecto de

50 SSTS, Sala 2ª de 27.4.I994 (ROJ: STS 2970/1994; MP: Enrique Bacigalupo Zapater); y I5.4.I994 (ROJ: STS 2502/I994; MP: Enrique Bacigalupo Zapater).

${ }^{51} \mathrm{LO} 7 / 2003$, de 30 de junio, de medidas de reforma para el cumplimiento íntegro y efectivo de las penas (BOE núm. I56, de 1.07.2003).

$5^{2} \mathrm{LO}$ I/20I5, de 30 de marzo, por la que se modifica la LO Io/I995, de 23 de noviembre, del CP (BOE núm. 77, de 31.03 .2015$)$.

53 STS, Sala 2a , de 27.04.20I6 (ROJ: STS I931/20I6; MP: Juan Ramón Berdugo Gómez de la Torre). 
esta sentencia más antigua, ya no podrán ser objeto de posteriores operaciones de acumulación en relación con las demás sentencias restantes. Sin embargo, si la acumulación no es viable, nada impediría su reconsideración respecto de cualquiera de las sentencias posteriores, acordando su acumulación si entre sí son susceptibles de ello. Es claro que la acumulación no es posible cuando las fechas lo impidan. Puede ser dudoso cuando su eventual resultado no permite el establecimiento de un límite máximo de cumplimiento efectivo, por ser mayor este que la suma de las penas efectivamente impuestas. Pero no se aprecian obstáculos insuperables para entender que acumular supone, en realidad, la realización de la operación completa prevista en el art. $76 \mathrm{CP}$, y no solo la posibilidad de considerarla ${ }^{54}$. De esta forma, no cabrá la acumulación a la sentencia más antigua, que es la que primero se debe examinar, cuando el límite máximo sea superior a la suma de las penas impuestas, lo que permitiría la reconsideración de todas las descartadas en la primera operación para el examen de otra posibilidad de acumulación distinta. Esta deberá limitarse a las condenas que, dadas las fechas de los hechos y de las sentencias, sean acumulables entre sís5.

Ello ha determinado la reunión del Pleno no Jurisdiccional de la Sala $2^{\mathrm{a}}$ TS de 3.02.2016, que aprobó el siguiente Acuerdo en aras a la interpretación del apartado controvertido: «la acumulación de penas deberá realizarse partiendo de la sentencia más antigua, pues al contenerse en ella los hechos enjuiciados en primer lugar, servirá de referencia respecto de los demás hechos enjuiciados en las otras sentencias. A esa condena se acumularán todas las posteriores relativas a hechos cometidos antes de esa primera sentencia. Las condenas cuya acumulación proceda respecto de esta sentencia más antigua, ya no podrán ser objeto de posteriores operaciones de acumulación en relación con las demás sentencias restantes. Sin embargo, si la acumulación no es viable, nada impediría su reconsideración respecto de cualquiera de las sentencias posteriores, acordando su acumulación si entre sí son susceptibles de ello».

El TS lo que establece no es un principio sustantivo penal sino una regla práctica y metodológica sobre el modo de proceder en la acumulación jurídica de las penas, fijando un criterio uniforme para su realización práctica, de forma que ello no debe impedir, a partir de dicho esquema, la posibilidad de su reconsideración teniendo en cuenta los principios sustantivos que deben tenerse en cuenta en esta materia, lo que desde luego no puede

54 STS, Sala 2a , de I9.II.20I5 (ROJ: STS 4729/20I5; MP: Miguel Colmenero Menéndez de Luarca).

55 A estos efectos se entiende precisa la STS, Sala $2^{\text {a }}$, de 26.02.20I6 (ROJ: STS 670/20I6 ; MP: Miguel Colmenero Menénez de Luarca), que expresa que «cabría rechazar cualquier acumulación cuyo resultado fuera menos favorable que otra posible, la interpretación de la nueva regulación no debería impedir que, tras un primer intento de acumulación, (o varios, en su caso), se acuda a otras distintas posibilidades, si resultan más favorables para el penado, criterio que resultaría aplicable en atención a la finalidad de la norma, orientada a reducir a un límite máximo racional la extensión de privación de libertad de una persona por hechos cometidos en un determinado lapso temporal. Siempre respetando el límite antes mencionado, es decir, siempre que todos los hechos por los que han recaído las distintas condenas sean anteriores a la sentencia más antigua de las que concretamente se acumulan». En este extremo es muy significativa también la STS, Sala $2^{\mathrm{a}}$, de 25.02.20I6 (ROJ: STS 828/20I6; MP: Juan Saavedra Ruiz), que razona como «la nueva redacción actualmente vigente del artículo 76.2, ha suscitado recientemente la reinterpretación del alcance de la acumulación cuando se trata de penas impuestas en distintos procesos». 
excluir otras posibilidades combinatorias siempre y cuando no se traspasen las reglas fijas e inamovibles establecidas tradicionalmente por el TS, esto es, que los hechos sean siempre anteriores a la sentencia que sirve de referencia a la acumulación, que los mismos no estén sentenciados con anterioridad a la misma y que la operación debe ser completa. De ahí la necesidad de establecer una regla metodológica que recoja en principio el punto de partida de la totalidad de las penas potencialmente acumulables. Según ello, cuando el art. 76.2 se refiere a que los hechos objeto de acumulación hayan sido cometidos antes de la fecha en que hubieren sido enjuiciados los que sirven de referencia, ello no significa necesariamente que esta sentencia deba ser la de fecha más antigua de todas las potencialmente acumulables sino anterior a las que hayan enjuiciado los hechos que sean objeto de acumulación en relación con la que sirve de referencia en cada caso. De la misma forma, cuando el límite máximo sea superior a las penas impuestas, podrá reconsiderarse la combinación de las descartadas en la primera operación para el examen de otra posibilidad de acumulación distinta, siempre que se cumplan las reglas fijas señaladas más arriba.

En relación con lo que el TS ha denominado «patrimonio punitivo» ${ }^{6}$ es claro que el sistema acogido por nuestro CP no puede sellar la posibilidad del mismo de manera absoluta pues ello es consecuencia del funcionamiento del propio sistema que limita la suma aritmética que representa la acumulación material introduciendo un límite cuantitativo que abarca penas impuestas en distintos procesos por hechos no enjuiciados y sentenciados con anterioridad a una sentencia precedente que se tome como referencia. La función de garantía a estos efectos está constituida por las reglas fijas establecidas. La interpretación sustantiva del sistema de acumulación jurídica no puede prescindir de determinados valores constitucionales como son los principios proclamados en el art. I5 CE relativo a las penas inhumanas, el art. $25 \mathrm{CE}$ que proclama que las penas privativas de libertad están orientadas hacia la reeducación y reinserción social y el propio art. I0.2 CE que obliga a la interpretación conforme a los tratados y acuerdos internacionales y a la Declaración Universal de Derechos Humanos ${ }^{57}$.

En definitiva, de esta norma se deduce, en primer lugar, la plena asunción de la doctrina jurisprudencial, eliminando la exigencia de conexidad para la refundición de condenas, al acoger un criterio exclusivamente temporal. En segundo lugar, que la fecha que determina el límite para la refundición es la celebración del juicio que da lugar a la primera condena -«la fecha en que fueron enjuiciados»-, no la fecha de la sentencia, ni la de su firmeza. Y, en tercer lugar, una interpretación que puede ser perjudicial para el reo en la determinación de la sentencia que marca la acumulación, pues concretándola necesariamente en la primera cabe la posibilidad de excluir de la aplicación del límite legal hechos cometidos en una misma época, pero posteriores a la primera condena. Hechos que podrían haberse incluido en la refundición si se escogiese, para determinarla, la sentencia

${ }^{6}$ STS, Sala $2^{\text {a }}$, de 14.02.2007 (ROJ: STS 1950/2007; MP: Francisco Moteverde Ferrer); 6.04.2004 (STS 2342/2004; MP: Cándido Conde-Pumpido Tourón); y I5.07.2002 (STS 5317/2002; MP: Luis Ramón Puerta Luis), entre otras muchas.

57 Así, por ejemplo, el art. 49.3 de la Carta de los Derechos Fundamentales de la Unión Europea (DOUE núm. 83, de 30.03.20I0), proclama que la intensidad de las penas no deberá ser desproporcionada en relación con la infracción 
que resultase más favorable para el reo, es decir la que pudiera abarcar un mayor número de hechos delictivos. En cualquier caso, ha de tomarse en consideración que esta refundición determinada temporalmente por la primera sentencia condenatoria, no excluye la posibilidad de repetir la operación con otros hechos y sentencias posteriores, formando un segundo grupo de condenas acumulables si, aplicando los límites legales, el resultado fuese favorable para el $\mathrm{reo}^{58}$.

\section{Firmeza de la sentencia}

Teniendo en cuenta que el art. 988 LECRIM dispone que la acumulación se realizará por el Juez o Tribunal que hubiese dictado la última sentencia, ello implica que son acumulables todas las condenas por delitos que no estuviesen ya sentenciados en el momento de la comisión del hecho que ha dado lugar a esta última resolución, o a la que determine la acumulación, con independencia de que tuviesen analogía o relación entre sí, pues todos ellos podrían haber sido enjuiciados en un solo proceso. Conforme a la jurisprudencia del TS59, en principio, deben únicamente excluirse, de un lado, los hechos que ya estuviesen sentenciados cuando se inicia el periodo de acumulación contemplado, es decir cuando se comete el delito enjuiciado en la sentencia que determina la acumulación, y de otro, los hechos posteriores a la sentencia que determina la acumulación. Y ello porque ni unos ni otros podrían haber sido enjuiciados en el mismo proceso. Es decir, aun cuando la doctrina del TS acoge un criterio favorable al reo en lo que se refiere a la práctica superación del requisito de la analogía o relación entre los delitos, criterio que se inspira en el principio constitucional de humanización de las penas, ello no quiere decir, que la acumulación jurídica de penas carezca de límites temporales o que la invocación genérica de dicho principio constitucional determine en cualquier caso la acumulación sin atender a ningún límite. Ello por cuanto constituye una exigencia legal ineludible, fundada en poderosas razones de tutela de los bienes jurídicos protegidos por el Derecho Penal, cumplir los referidos requisitos temporales que son los que determinan la imposibilidad de acumular penas impuestas por delitos que ya estuviesen sentenciados cuando se cometió el delito que dio lugar a la sentencia que delimita la acumulación, pues es claro que dichos delitos en ningún caso hubiesen podido ser juzgados conjuntamente. Como señala el TS ${ }^{60}$, lo que pretendía el art. 70.2 in fine del CP anterior -y reiteró el art. 76.2 CP actual-, es que a todos los supuestos de concurso real de delitos se les dé el mismo tratamiento, con independencia de que los hechos se hayan enjuiciado o no en un mismo proceso, siempre que el enjuiciamiento conjunto hubiese sido posible. Pero tal regulación no pretende constituir a los ya sentenciados en poseedores de un patrimonio punitivo que les provea de

$5^{8}$ La STS, Sala $2^{a}$, de 24.04.2015 (ROJ: STS I893/2015, MP: Perfecto Agustín Andrés Ibáñez), afirma que «producida, según esto, la acumulación de las penas de algunas de las sentencias a examen, cabrá formar un nuevo o nuevos grupos con las restantes, actuando de idéntico modo».

59 SSTS, Sala $2^{\text {a }}$, de 25.06.2009 (ROJ: STS 4902/2009; MP: Juan Saavedra Ruiz); I7.06.2009 (ROJ: STS 4844/2009; MP: Juan Saavedra Ruiz); y I2.II.2007 (ROJ: STS 7489/2007; MP: Francisco Monteverde Ferrer).

60 Entre otras, SSTS, Sala $2^{a}$, de 8.05.2000 (ROJ: STS 3735/2000; MP: Cándido Conde-Pumpido Tourón); 2I.I2.I998 (ROJ: STS 7778/I998; MP: Cándido Conde-Pumpido Tourón); y Io.03.I998, cit. 
inmunidad o de una relevante reducción de penalidad, para los delitos futuros, es decir los que puedan cometer después del cumplimiento de su condena, o durante la misma tanto en caso de quebrantamiento como de delitos ejecutados durante los permisos o en el interior de la prisión, esto es para aquellos delitos que sin ser susceptibles de acumulación, rebasarán el límite del art. 76, lo que sería injusto y atentaría a los principios que rigen el proceso penal ${ }^{61}$, insistiéndose en que tales limites no pueden operar como garantía de impunidad para el futuro, aunque se hayan agotado los límites máximos establecidos con carácter general por la Ley para las penas privativas de libertad ${ }^{62}$.

En cuanto a la fecha de condena a la que hay que atender, el dato clave es la fecha de la sentencia y no la de su firmeza ${ }^{6}$. No cabe la refundición con condenas por hechos cuya fecha de comisión sea posterior a la fecha de la sentencia a refundir, aunque anterior a su firmeza. Sobre esta cuestión el Acuerdo del Pleno No Jurisdiccional de la Sala $2^{\mathrm{a}}$ TS de 29.II.2005, dispuso que la fecha a tener en cuenta para cerrar ese ciclo cronológico no es la fecha de la sentencia firme, sino la fecha de la sentencia condenatoria definitiva, habiendo mantenido también que, por no poderse juzgar en un mismo proceso, no es posible materialmente la acumulación de ciertos delitos -como el quebrantamiento de condena, respecto a la sentencia en ejecución-, o los delitos cometidos en el seno de la propia institución penitenciaria, cuyo ingreso quedó determinado por la condena previa. Por tanto se estima innecesaria la firmeza de la sentencia para el límite de la acumulación. Hay que atender a la fecha de la primera sentencia, y no la de apelación o casación.

Algún sector defendió incluso que la decisiva es la fecha de celebración del juicio o vista oral, en la medida en que hasta ese momento potencialmente es factible la incorporación al enjuiciamiento de delitos conexos. Esta posición tuvo algún eco jurisprudencial ${ }^{64}$ a raíz de la última reforma del art. $76 \mathrm{CP}$ operada por LO I/2015, que sustituyó el término sentenciados por enjuiciados. Pero, salvando el equívoco producido por ese retoque legal, el Pleno No Jurisdiccional de la Sala $2^{\text {a }}$ de 3.02.20I6, ha refrendado el criterio tradicional, hay que estar a la fecha de la sentencia, no la del juicio. Tal opción interpretativa no solo aporta precisión -las sesiones del juicio pueden extenderse varios días, mientras que la fecha de la sentencia es única y aparece en la hoja histórico penal-, sino que además favorece al penado, responde más fielmente a la filosofía que inspira ese dique cronológico y no es incompatible con la literalidad de la ley. Sentenciados es una de

${ }^{6}$ I STS, Sala 2a , de 9.05.2000 (ROJ: STS 3780/2000; MP: Andrés Martínez Arrieta).

62 STS, Sala 2a , de 8.02.I999 (ROJ: STS 779/1999; MP: José Antonio Martín Pallín).

63 En esta cuestión encontramos que mientras algunas sentencias han exigido la firmeza de la sentencia, como la STS, Sala 2a de I6.05.2003 (ROJ: STS 3305/2003; MP: Miguel Colmenero Menéndez de Luarca), otras resoluciones no se han referido para nada a la misma y, en consecuencia, no la han tenido en cuenta, como la STS, Sala $2^{a}$, de 9.06.2003 (ROJ: ROJ: STS 3967/2003; MP: Joaquín Giménez García); y finalmente otras, como la STS, Sala $2^{a}$, de 10.05.2002 (ROJ: STS 3313/2002; MP: José Manuel Maza Martín), que no solo no exigían la firmeza de la sentencia, sino que además, razonaban el porqué de la inexistencia de este requisito, disponiendo «Aún cuando en alguna resolución precedente de este mismo Tribunal se haya hecho referencia a la fecha de la firmeza de la sentencia en supuestos de acumulación, (...) no es menos evidente que, identificar semejante límite temporal con la fecha de la firmeza en casos como el presente, se vería burlado el requisito expreso establecido en la norma penal (...) cual es la obligada posibilidad de enjuiciamiento conjunto de los delitos cuyas penas se refunden».

64 STS, Sala 2a , de II.06.20I5 (ROJ: STS 2597/20I5; MP: Juan Ramón Berdugo Gómez de la Torre). 
las diversas acepciones del término enjuiciados. El $\mathrm{TS}^{65}$ ya ha había destacado con anterioridad que la firmeza de la sentencia nada añade a la imposibilidad de acumular hechos ya sentenciados. Reconocía, no obstante, la falta de uniformidad jurisprudencial en este aspecto. Hasta el citado Acuerdo de 2005 convivían resoluciones en sentidos diversos $^{66}$, pero actualmente el criterio de no exigir la firmeza está consolidado ${ }^{67}$. En conclusión, hay que estar a la fecha de la sentencia y no a la del juicio, y concretando más, a la fecha de la sentencia de instancia y no la de apelación o casación.

En definitiva, una vez sentenciados unos hechos, aunque esté pendiente un recurso, no es posible el enjuiciamiento conjunto con causas seguidas por hechos posteriores y por tanto nunca puede hablarse de hechos que podrían haberse enjuiciado conjuntamente. El fundamento de ese límite temporal es evitar la conciencia de impunidad por los delitos sucesivos $^{68}$. De admitirse otra tesis llevando el límite a la fecha de la firmeza se privilegiaría a quien interpone un recurso, aunque sea infundado, para desplazar esa fecha en el tiempo, frente a quien acata la sentencia. Deben, pues, entenderse como épocas diferentes no acumulables las que se encuentren separadas por la existencia de alguna sentencia condenatoria aunque no sea firme ${ }^{69}$. Excepcionalmente se ha excluido la refundición de penas por hechos que aún habiéndose cometido con anterioridad a la fecha de la sentencia que determina la acumulación, por su propia esencia no podían haber sido objeto de enjuiciamiento en un único procedimiento ${ }^{70}$.

65 STS, Sala $2^{\text {a }}$, de 21.07.2005, cit.

66 Exigieron la firmeza de la sentencia, entre otras, las SSTS, Sala $2^{\mathrm{a}}$, de 16.05.2003 (ROJ: STS 3305/2003; MP: Miguel Colmenero Menéndez de Luarca); I2.05.2003 (ROJ: STS 32I7/2003; MP: José Antonio Martín Pallín); I4.Io.2002 (ROJ: STS 7024/2002; MP: Joaquín Martín Canivell); y 19.07.2002 (ROJ: STS 5520/2002;; MP: Miguel Colmenero Menéndez de Luarca). Las SSTS, Sala $2^{a}$, de 2.10.2000 (ROJ: STS 6965/2000; MP: Joaquín Giménez García); y I5.05.2002 (ROJ: STS 3313/2002; MP: José Manuel Maza Martín), mantuvieron otro criterio. De la primera de ellas extraemos la siguiente reflexión, «sin embargo en las más recientes (sentencias) ya se elimina el requisito de la firmeza porque nada añade al hecho básico de que los hechos sean posteriores a la última sentencia que determina la acumulación, pues de un lado es evidente la imposibilidad de enjuiciamiento conjunto, y de otro el argumento relativo a la evitación del sentimiento de impunidad (...) quebraría de exigirse el requisito de la firmeza, al prolongarse indefinidamente en el tiempo la posibilidad de la acumulación hasta tanto recayere firmeza». A la segunda sentencia pertenece este comentario, «aún cuando en alguna resolución precedente de este mismo Tribunal se haya hecho referencia a la fecha de la firmeza de la sentencia en supuestos de acumulación,.. no es menos evidente que (de) identificar semejante límite temporal con la fecha de la firmeza en casos como el presente, se vería burlado el requisito expreso establecido en la norma penal (...) cual es la obligada posibilidad de enjuiciamiento conjunto de los delitos cuyas penas se refunden».

67 Entre otras muchas otras, SSTS, Sala $2^{a}$, de I2.09.20I3 (ROJ: STS 4II7/20I3; MP: Manuel Marchena Gómez); y I6.03.20II, cit., conforme a la cual «lo relevante a tal efecto es la fecha en que se dictó la primera sentencia, pues a partir de este momento ya no cabe que los hechos delictivos posteriores pudieran haberse enjuiciado junto con el ya sentenciado».

68 Como gráficamente afirma la STS, Sala 2a , de 2I.0I.20I4 (ROJ: STS 349/20I4; MP: Manuel Marchena Gómez), «no existe en nuestro sistema un derecho fundamental a la impunidad de los delitos cometidos cuando ya ha sido fijado un límite máximo de cumplimiento como consecuencia de la acumulación de condenas practicada».

69 SSTS, Sala 2a ${ }^{\text {a }}$ de 3.04.2007 (ROJ: STS 2393/2007; MP: Joaquín Delgado García); 31.03.2006 (ROJ: STS 1853/2006; MP: Joaquín Delgado García); y 16.06.2005 (ROJ: STS 3946/2005; MP: Joaquín Delgado García).

70 Este es el caso contemplado en la STS, Sala 2a , de I7.07.2000 (ROJ: STS 5964/2000; MP: Joaquín Delgado García), en el que se rechaza la posibilidad de acumular las penas impuestas en dos sentencias dado que el último delito (falso testimonio) se había cometido durante la celebración del juicio oral relativo al primero (dos delitos de calumnia). 
Asimismo, resulta igualmente relevante mencionar que la firmeza de la correspondiente resolución judicial no ha sido un obstáculo para que el TS haya confirmado nuevas liquidaciones de condena dictadas tras la Sentencia Tribunal Europeo de Derechos Humanos (en adelante STEDH) de 2I.IO.20I373. A tales efectos manifestaba el TS $^{72}$ que respecto de condenas todavía en ejecución, no solo nada impide la rectificación del criterio hasta ahora aplicado para sustituirlo por otro más favorable al reo en el sentido que se desprende de la mencionada STEDH, sino que resulta obligado en tanto que no es posible mantener una situación de privación de libertad basándose en un criterio que, en circunstancias similares a las contempladas en la referida STEDH, vulnera derechos reconocidos en el Convenio Europeo de Derechos Humanos ${ }^{73}$.

\section{Cosa Juzgada}

En fase de ejecución se insertan algunos pronunciamientos que no son ejecutivos, sino estrictamente declarativos. Son decisiones que podrían incluirse en la sentencia pero que por razones diversas y a veces de pura operatividad procesal se postergan. En materia propiamente penal el más significado es el incidente de acumulación de condenas. En ese trámite se está aplicando derecho penal sustantivo, se está procediendo a concretar unas reglas penológicas previstas para el concurso real de delitos. Podría hacerse en la sentencia y así se hace cuando los diversos delitos son objeto de enjuiciamiento conjunto. Como eso es imposible hacerlo siempre en la sentencia, el legislador ha arbitrado un incidente que, aunque incrustado en la fase de ejecución, es puramente declarativo. Justamente por eso se concede un recurso -casación- que no aparece presente en otros supuestos, en ocasiones por la provisionalidad inherente a la misma decisión de que se trata. Las decisiones sobre acumulación causan firmeza. Podrá plantearse ante una nueva sentencia posterior si incide en la acumulación ya efectuada o denegada. Pero no si estuvo bien efectuada o denegada. Lo decidido en primera instancia y confirmado o variado por el TS, si es que se interpuso recurso, goza de firmeza y deviene intangible.

La jurisprudencia del TS ha mostrado posicionamientos distintos sobre este tema ${ }^{74}$,

7I STEDH, Gran Sala, de 21.I0.2013 (Demanda núm. 42750/09, Del Río Prado c. España).

72 SSTS, Sala 2a ${ }^{\text {a }}$ de 7.02.20I3 (ROJ: STS 657/20I4; MP: Alberto Gumersindo Jorge Barreiro); y 2.I2.2013 (ROJ: STS 59II/20I3; MP: Julián Artemio Sánchez Melgar).

73 Convenio para la Protección de los Derechos Humanos y de las Libertades Fundamentales, hecho en Roma el 4.II.I950, y enmendado por los Protocolos adicionales números 3 y 5, de 6.05.I963 y 20.0I.I966, respectivamente (BOE núm. 243, de Io.IO.I979).

74 Así la STS, Sala 2a , de I.07.I994 (ROJ: STS 5074/1994; MP: Cándido Conde-Pumpido Ferreiro), consideró aplicable la regla $2 .^{a}$ del art. $76 \mathrm{CP}$ a un caso en el que una de las condenas, que tuvo una singular rapidez en su tramitación, había sido incluso ya ejecutada, mientras que en el extremo opuesto, la STS, Sala $2^{a}$, de 30.05.I992, cit., asimismo estimó que había de aplicarse la regla 2. ${ }^{a}$ pese a que, por la excesiva lentitud del procedimiento, la condena había alcanzado firmeza después de liberado el preso por haber cumplido ya todas las penas acumuladas antes. La STS, Sala $2^{\mathrm{a}}$, de 20.05.I992 (ROJ: STS 4027/1992; MP: José Augusto de Vega Ruiz), se pronuncia en contra de que se incluya nueva condena en una acumulación ya ejecutada. Recoge asimismo la existencia de contradicción en la jurisprudencia la STS, Sala $2^{a}$, de 18.07.1996, cit. La STS, Sala $2^{\circ}$, de 22.I0.200I (ROJ: STS 8I3I/200I; MP: Joaquín Delgado García), expone que «el que unos procesos se hayan tramitado con rapidez y otros con lentitud puede propiciar que hechos ocurridos en una misma época sean enjuiciados y sustanciados en fechas muy distantes. Tan distantes que incluso puede ocurrir que algunas de las 
si bien, en los últimos tiempos ${ }^{75}$ se muestra a favor de ser incluidas si concurren los requisitos temporales exigidos para que pudieran haberse juzgado en un único procedimiento.

En consecuencia, el auto de acumulación ha de estar abierto, y no se puede hablar, en estos casos, de eficacia de cosa juzgada que pudiera impedir una nueva resolución en beneficio del penado, de manera que la existencia de acumulaciones anteriores no impide un nuevo examen de la situación cuando se conozcan nuevas condenas que pudieran ser susceptibles asimismo de acumulación. En estos casos no cabe hablar de eficacia de cosa juzgada que pudiera impedir una reconsideración del caso en beneficio del reo. Si aparecieran nuevas condenas por delitos no contemplados en la anterior resolución sobre acumulación, dictada conforme al art. 988 LECRIM, habrá de dictarse un nuevo auto para hacer un cómputo que abarque la totalidad de las condenas. Aunque la nueva acumulación que se opere solo será procedente cuando, en su conjunto, resulte favorable al reo, dado que la condena posterior no puede perjudicar retroactivamente la acumulación ya realizada ${ }^{76}$. Una vez que se entra a revisar una acumulación anterior, la revisión no se limita a las penas efectivamente acumuladas, sino a todas las que fueron objeto de examen en el Auto, sin perjuicio de que entonces su acumulación se considerara improcedente ya que sí podrían ser acumulables con la nueva sentencia ${ }^{77}$.

También es reiterada la jurisprudencia del $\mathrm{TS}^{78}$ sobre la naturaleza no definitiva de las liquidaciones de condenas. Las resoluciones que aprueban las liquidaciones de condena efectuadas al penado tienen, por su propia naturaleza, carácter provisional, pues pueden verse modificadas por las incidencias del cumplimiento, de mayor alcance cuando se trata de penas impuestas conforme al derogado CP I973. En consecuencia, la jurisprudencia no les ha reconocido los efectos propios de la cosa juzgada. Las resoluciones que aprueban las

penas correspondientes ya hayan sido ejecutadas (...) hacer depender la aplicación de una regla sustantiva de fijación de pena de circunstancias adjetivas o aleatorias, como puede ser la mayor o menor celeridad en la tramitación de una causa o en la ejecución de una pena, sólo puede conducir a soluciones absurdas, desiguales o injustas». RÍOS MARTÍN, J. C., Manual práctico para la defensa de las personas presas, Colex, Madrid, I997, pág. 124, hace referencia a la existencia de esta jurisprudencia contradictoria.

75 SSTS, Sala $2^{\text {a }}$, de 27.0I.20I5 (ROJ: STS 47I/20I5; MP: José Ramón Soriano Soriano); y 20.06.20I4 (ROJ: STS 243I/2014; MP: Julián Artemio Sánchez Melgar).

${ }^{6}$ Asimismo las SSTS, Sala 2a $2^{\text {a } 6.07 .2009 ~(R O J: ~ S T S ~ 5405 / 2009 ; ~ M P: ~ M a n u e l ~ M a r c h e n a ~ G o ́ m e z) ; ~ y ~}$ 22.05.2009 (ROJ: STS 3357/2009; MP: Manuel Marchena Gómez), argumentan que «se equivoca el Juez de lo Penal al tomar como referencia determinante de la acumulación la sentencia por él dictada, ya que el hecho de que el art. 988 LECRIM adjudique la competencia para la fijación del límite de cumplimiento al Juez o Tribunal que hubiere dictado la última sentencia, encierra tan solo un criterio de atribución competencial, pero no impone que esa última resolución, en atención a su fecha, sea la que inspire la procedencia o improcedencia de la acumulación interesada».

77 STS, Sala 2a , de 7.05.20I4 (ROJ: STS I930/2014; MP: Andrés Palomo del Arco).

${ }^{78}$ STS, Sala $2^{a}$, de 30.09.20I4 (ROJ: STS 4355/20I4; MP: Andrés Palomo del Arco), conforme a la cual «El proceso de ejecución de las distintas penas impuestas a una persona, en una o varias sentencias, y tenga o no establecido un determinado máximo de cumplimiento, se extienda al tiempo preciso desde que comienza la ejecución hasta que se produce el licenciamiento definitivo, y en ese periodo temporal pueden aparecer distintas incidencias que son resueltas con aplicación del criterio que, a través de la interpretación de la ley, se establezca como correcto en cada caso». En la misma línea, SSTS, Sala $2^{a}$, de 3.05.20II (ROJ: STS 2864/20Ir; MP: Miguel Colmenero Menéndez de Luarca); 27.I0.20II (ROJ: STS 7386/20II; MP: Andrés Martínez Arrieta); y 29.I0.2009 (ROJ: STS 8008/2009; MP: Miguel Colmenero Menéndez de Luarca). 
liquidaciones de condena efectuadas al penado tienen, por su propia naturaleza, carácter provisional y la jurisprudencia no les ha reconocido los efectos propios de la cosa juzgada.

\section{Abono de la prisión preventiva}

En un primer momento el TC79 declaró constitucionalmente ilegítima la exclusión para el cumplimiento de la pena del tiempo pasado en prisión provisional por el mero hecho de ser coincidente con la condición de penado en otra causa. Posteriormente el TC precisa que la previsión legal del art. 58.I CP, en la redacción anterior a la Ley Orgánica (en adelante LO) $5 / 2010^{80}$, no puede aplicarse a supuestos distintos a los que contempla y justifican el precepto, «dado que una interpretación aparentemente amparada en el enunciado literal de la norma pero que desconoce su finalidad, provoca un efecto no querido por esta; pues si el mismo tiempo de privación material de libertad se descuenta varias veces de la sanción prevista para varios hechos, la rebaja en el cumplimiento de las penas impuestas depende de una circunstancia procesal totalmente imprevisible y azarosa: el número de causas que se abran en investigación de los hechos. De esta manera queda completamente desvirtuada la finalidad de la norma, prevista, repetimos, para una sola causa y una sola condena» ${ }^{81}$. Por ello no era irrazonable que se denegara el abono del mismo tiempo de prisión provisional para el cumplimiento de varias causas, tomando en consideración el tenor del enunciado del art. 58.I CP entonces vigente, en atención al fundamento y la finalidad de la norma. Para fundamentar esta última precisión el $\mathrm{TC}^{82}$ ha rechazado que de la lectura conjunta de los arts. 58.I, 75 y 76 CP la pretensión de descontar doblemente las prisiones provisionales sufridas del tiempo máximo del límite temporal correspondiente, sea constitucionalmente obligada. Al efecto destaca este Tribunal el argumento por el que la exclusión del abono reiterado del mismo tiempo de prisión

79 STC 57/2008, Sala 2a , de 28.04.2008 (BOE núm. I35 de 4.06.2008; MP: Vicente Conde Martín de Hijas). La cuestión suscitada se contraía a determinar si ha resultado vulnerado el derecho del recurrente en amparo a la libertad por no haberle sido abonado la totalidad del tiempo de privación de libertad sufrido preventivamente para el cumplimiento de la pena impuesta en una misma causa, habiendo excluido el órgano judicial del referido abono el tiempo en el que el recurrente, simultáneamente a la situación de prisión provisional en dicha causa, se encontraba privado de libertad como penado para el cumplimiento de la condena impuesta en otra causa distinta. Según el TC, si el legislador, al regular el abono del tiempo de privación de libertad sufrido provisionalmente para el cumplimiento de la pena o pena impuestas en la misma causa (art. 58.I CP), no hizo ninguna mención al no abono del tiempo en el que simultáneamente han coincidido las situaciones de prisión provisional en una causa y de penado en otra, fue sencillamente porque no quiso hacerlo. Tampoco puede considerarse que, en la situación de coincidencia temporal de las situaciones de prisión provisional por una causa y de ejecución de pena de prisión por otra, la prisión provisional no afecte realmente a la libertad, pues es preciso tener en cuenta que, de conformidad con lo dispuesto en la normativa penitenciaria, el cumplimiento en calidad de penado se ve directa y perjudicialmente afectado por el hecho de coincidir con una situación de prisión provisional decretada, pues el penado que se encuentra con causas pendientes en situación de prisión provisional no puede acceder a ningún régimen de semilibertad, no puede obtener permisos, ni puede obtener la libertad condicional.

${ }^{80}$ LO 5/20IO, de 22 de junio, por la que se modifica la LO IO/I995, de 23 de noviembre, del CP (BOE núm. 52 , de 23.06.2010).

8i SSTC I48/20I3, cit.; у 92/20I2, Sala I ${ }^{a}$, de 7.05.20I2 (BOE núm. I34 de5.06.20I2; MP: Pascual Sala Sánchez).

82 SSTC 168/2013, Sala 2a de 7.I0.2013 (BOE núm. 267 de 7.II.2013; MP: Enrique López y López); y I48/2013, Sala 2a , de 9.09.2013 (BOE núm. 242 de 9.IO.20I3; MP: Juan José González Rivas). 
provisional, tomaba mayor intensidad en el caso de aplicación del límite «máximo de cumplimiento efectivo de la condena» previsto en el art. 76 CP. En conclusión, dice nuestro TC que «la decisión judicial de no descontar del límite máximo de cumplimiento efectivo (...), el periodo de tiempo en que simultáneamente se encontraba como preso preventivo y como penado no es contraria a la CE. Es decir, no es constitucionalmente exigible, en tales casos, una interpretación conjunta del art. 58. I -en la redacción anterior a la LO 5/2010- y de los arts. 75 y $76 \mathrm{CP}$, que imponga el doble cómputo de un mismo periodo de prisión como preventivo y como penado, o que lleve a considerar que el tiempo de prisión provisional simultáneo al de cumplimiento de pena, deba conceptuarse como tiempo de cumplimiento efectivo» ${ }^{83}$.

Y la misma conclusión se alcanza por el $\mathrm{TS}^{84}$ declarando que de la interpretación inicial del TC, en rigor, podría deducirse que si en un mismo periodo de tiempo una persona está en prisión preventiva por varias causas, habrá de abonarse a las penas recaídas en cada uno de los distintos procedimientos. Con arreglo a esta interpretación un mismo día de estancia efectiva en prisión podría llegar a valer por dos o incluso por tres o por cuatro, si el interno está cumpliendo una condena y simultáneamente en prisión preventiva por tres causas diferentes. Ello dependería de factores tremendamente aleatorios, como el mayor o menor rigor con que se apliquen la conexidad y el art. 300 LECRIM, la cronología de la firmeza de cada sentencia, la coordinación entre los distintos Juzgados, etc. De la dicción de la norma ${ }^{85}$ se ha pasado a la razonabilidad de la interpretación ${ }^{86}$. Una exégesis que excluye el doble abono de un mismo periodo de prisión provisional es muy razonable pese a que no sea el más exactamente ajustado a la literalidad de los arts. $33 \mathrm{CP}$ y $58 \mathrm{CP}$ antes de la reforma de 20Io. La aplicación inmatizada de una reducción doble del tiempo simultaneado entre la prisión provisional y como penado, si se proyecta sobre el límite máximo y no sobre el total de la suma aritmética conduce al absurdo de que en muchos casos cumplirá menos pena quien más delitos haya cometido ${ }^{87}$.

${ }_{3}$ STC 35/2014, Pleno, de 27.02.20I4 (BOE núm. 73, de 25.03.20I4; MP: Enrique López y López).Y vuelve a repetirlo en STC 70/20I4, Sala 2 ${ }^{\text {a }}$, de 5.05.20I4 (BOE núm. I35 de 4.06.20I4; MP: Fernando Valdés Dal-Ré), al afirmar que «no es constitucionalmente exigible, en tales casos, una interpretación conjunta del art. 58.I CP -en la redacción anterior a la LO 5/20I0- y de los arts. 75 y 76 CP, que imponga el doble cómputo de un mismo periodo de prisión como preventivo y como penado, o que lleve a considerar que el tiempo de prisión provisional simultáneo al de cumplimiento de pena, deba conceptuarse como tiempo de «cumplimiento efectivo». Y de igual forma la STC 80/20I4, Sala $2^{2}$, de 28.05.20I4 (BOE núm. I53 de 24.06.20I4; MP: Adela Asua Batarrita), descartó también que fuera aplicable la doctrina de la STC 57/2008, pues en absoluto da sustento a que el descuento del periodo simultáneo de preventiva opere sobre el tope máximo fijado de cumplimiento efectivo que resulta de la acumulación jurídica de las condenas, no regulada en el art. 58.I CP, sino en el art. 76 CP. Y en el propio sentido

84 STS, Sala 2ª de 10.07.2012 (ROJ: STS 5346/2012; MP: Antonio del Moral García).

85 Argumento prioritario, aunque no exclusivo de la STC 57/2008, cit.

${ }^{86}$ STC 90/2012, Sala I ${ }^{a}$, de 7.05.20I2 (BOE núm. I34 de 5.06.2012; MP: Pablo Pérez Tremps).

$87 \mathrm{Si}$ se parte de otra interpretación se llegaría al absurdo de entender que el condenado por un solo delito a una pena de 20 años será de peor condición que el condenado por ese mismo delito y además por otro cuya pena comenzó a cumplir mientras estaba en prisión preventiva por aquél. Si ese segundo delito tiene asignada, por ejemplo, una pena de 4 años resultará que su máximo de cumplimiento será de 20 años que con la reducción de la prisión preventiva padecida se convertirían en I8, si duró dos años la prisión preventiva, o incluso en I6, si se extendió la prisión provisional durante el total de cumplimiento de cuatro años. Quien solo cometió el primer delito no contará con esa rebaja adicional. Ni siquiera aunque haya estado en prisión 
En cuanto a la posible repercusión que pueda tener la ya citada STEDH de 2I.I0.20I3, sobre la doctrina del doble cómputo de la prisión preventiva en los casos de coincidencia con cumplimiento, declara el $\mathrm{TS}^{88}$ que de forma directa la referida STEDH no tiene incidencia alguna en el tema referido al abono doble de la prisión preventiva, entendiendo que no tienen la misma naturaleza las redenciones ordinarias y extraordinarias que procedan y el abono de la prisión preventiva. Tales redenciones son avatares procesales que se producen durante el cumplimiento de una pena en ámbito de ejecución penitenciaria, esto es, se trata de beneficios penitenciarios, mientras que el abono de la prisión preventiva, resultante del art. $58 \mathrm{CP}$, no es más que una operación de liquidación de una condena, resultado de restar de su duración el tiempo pasado como consecuencia de la referida aplicación de la medida cautelar personal denominada prisión provisional. La STEDH en cuestión se refería a la proscripción de una retroactividad desfavorable para el reo en cuanto a la forma de interpretación del cumplimiento sucesivo de penas hasta los límites legales que resultan del art. $76 \mathrm{CP}$-antes $70 \mathrm{CP}$ 1973-, y nada tiene que ver, en consecuencia, con el problema relativo al abono del doble cómputo de la prisión provisional en los supuestos de acumulación jurídica de condenas.

\section{Condenas dictadas por Tribunales extranjeros}

Al margen de toda la problemática que conllevan las relaciones internacionales en el ámbito penal ${ }^{89}$, no hay mayores inconvenientes para que una sentencia extranjera, una vez superado el proceso de reconocimiento, pudiera ser incluida en una acumulación. El TS ha tratado la cuestión de la acumulación de condenas en el extranjero en diversas resoluciones distinguiendo las siguientes situaciones.

\section{X.I. Hasta la publicación de la Decisión Marco 2008/675/JAI}

En este caso podemos encontrarnos con supuestos diferentes. En primer lugar, aquellos en donde se acepta la acumulación de condenas impuestas por tribunales extranjeros, cuyo cumplimiento tiene lugar en España en virtud de un tratado internacional sobre cooperación en materia de ejecución de sentencias penales, sobre la base de lo establecido en la ley española aplicable si en el Tratado no existe norma alguna al

preventiva un número semejante de años por ese único delito, lo que arrastra los mismos eventuales perjuicios. La misma pena impuesta a los dos partícipes de un mismo delito, tendrá una duración efectiva muy inferior para uno de ellos por la extraña razón de que además había cometido otro delito cuya pena comenzó a cumplir cuando estaba en prisión preventiva por el delito más grave. A medida que sea mayor el número de delitos, es más probable la existencia de prisiones preventivas simultaneándose con condenas y por tanto la posibilidad de dobles abonos.

88 STS, Sala 2a , I0.06.20I4 (ROJ: STS 3II4/20I4; MP: Julián Artemio Sánchez Melgar).

89 Bujosa VADELL, LM., «Reconocimiento y ejecución de sentencias penales extranjeras», en Diario La Ley núm. 5350, de I2.07.200I, pág. I777, señala la clara tendencia existente dentro del marco de la Unión Europea «a favor de una cooperación más estrecha, más eficaz y más rápida basada en el principio de confianza mutua entre Estados miembros en orden a conseguir la libre circulación de sentencias penales en el espacio europeo de justicia». 
respecto $^{90}$. Entiende el TS que los arts. 70.2 CP I973 ó 76 CP resultan aplicables en estos supuestos por cuanto que los mismos no contienen ninguna exclusión al respecto. La reglas que limitan la acumulación aritmética de las penas en los casos de concurso real, sobre todo en un sistema como el nuestro, que excluye las penas perpetuas privativas de la libertad, tienen la finalidad de no eliminar el carácter temporal de la pena así como la de unificar la reprobación del hecho mediante un símbolo único del reproche. Ninguna de estas finalidades deja de tener sentido cuando una de las penas ha sido impuesta por un tribunal extranjero. Por tanto, las reglas contenidas en los artículos anteriormente citados pueden en principio ser aplicadas tanto a sentencias nacionales como extranjeras. En definitiva, el TS admite la acumulación de una condena impuesta por un Tribunal extranjero cuyo cumplimiento y ejecución no se ha producido en el extranjero sino en nuestro país en virtud de un tratado internacional, que remite su ejecución física y jurídicamente a España. Pero ello no como principio absoluto, sino que se procederá así en principio y ello dependerá de lo establecido en el Tratado sobre cooperación en materia de ejecución de sentencias, que es también aplicable.

En segundo lugar, supuestos que deniegan la acumulación de una pena de prisión impuesta por sentencia de la jurisdicción extranjera que ya ha sido cumplida en el extranjero antes de que el recurrente fuera extraditado a España, simplemente porque esos distintos hechos, los realizados en España y en el extranjero, en modo alguno pudieron ser objeto del mismo proceso, por haber ocurrido en territorios nacionales distintos, es decir, sometidos a la soberanía de diferentes Estados y, por tanto, enjuiciados por jurisdicciones nacionales diferentes ${ }^{91}$. No se trata de un simple obstáculo procesal, como ocurre cuando en tribunales de la misma jurisdicción nacional no se celebra un solo juicio sino varios para conocer de los diferentes delitos que podrían haber sido objeto de un solo procedimiento. El hecho de haberse cometido las diferentes infracciones penales en territorios sometidos a soberanías estatales distintas cuando el enjuiciamiento se produjo en otro país y allí se ha cumplido la pena, hace que la jurisdicción española tenga que considerarse ajena a lo enjuiciado en este otro país, incluso a los efectos de acumulación de condenas. Este supuesto se diferencia claramente de la situación expuesta anteriormente en la que sí había un convenio en virtud del cual se entrega a un súbdito español que ha delinquido en otro país para cumplir aquí la pena allí impuesta. Por virtud de un acuerdo internacional hubo una voluntaria limitación de los derechos de soberanía de aquel país extranjero en favor de la soberanía de España, que se consideró razón suficiente para integrar la condena penal extranjera en una refundición de penas junto con las condenas españolas.

En tercer lugar, supuestos en los que se admite la acumulación, en una sola, de la condena privativa de libertad impuesta al penado en sentencia dictada por la jurisdicción española con la impuesta en el expediente de cumplimiento de condena derivado de sentencia dictada por un tribunal extranjero ${ }^{92}$, por cuanto que, además de existir conexión temporal, con arreglo al art. 23.4 f. LOPJ el hecho cometido en el extranjero pudo haber sido

\footnotetext{
90 STS, Sala $2^{a}$, de 27.06.2000 (ROJ: STS 5235/2000; MP: Enrique Bacigalupo Zapater), entre otras.

91 STS, Sala 2 a , de I8.I2.2002 (ROJ: STS 8580/2002; MP: Joaquín Delgado García).

$9^{2}$ STS, Sala $2^{a}$, de 30.06.2005, (ROJ: STS 4387/2005; MP: Siro Francisco García Pérez).
}

REDUR I4 / 2016 
enjuiciado en España.

Finalmente, aquellos supuestos ${ }^{93}$ en los que procede la acumulación por resultar aplicable el Convenio sobre traslado de personas condenadas ${ }^{94}$. A su tenor, en aras de facilitar la cooperación y colaboración de los Estados firmantes, se autoriza el traslado desde el Estado de condena al Estado de cumplimiento de aquel penado que sea nacional del segundo, siempre que la sentencia dictada en el primero sea firme y concurran los demás presupuestos en dicho convenio establecidos. Se seguirán a partir del traslado las reglas de ejecución imperantes en el Estado de cumplimiento, sin que nada impida que la Audiencia Nacional haya asumido su competencia sobre la ejecución ex art. 65.2 LOPJ, ni que le sean de aplicación las reglas del arts. 76 CP. Es decir, la atribución jurisdiccional para ejecutar esa sentencia en España proviene de otro Convenio, en este caso del Consejo de Europa.

Como se observa, todas las resoluciones que permiten la acumulación tienen en común que se trata de una acumulación de condenas en la que concurren condenas impuestas en España con condenas dictadas en el extranjero en virtud de un Convenio internacional que determina su ejecución en España y la aplicación de la normativa española a esa ejecución. Ello por cuanto el art. 76.2 CP y el art. 988 LECRIM no permitían desplegar sus efectos sobre estas ejecutorias sin el complementario Convenio internacional que atribuía proyectar la normativa española a la ejecución de la sentencia extranjera. Por el contrario, la acumulación se deniega cuando esas condenas impuestas en el extranjero ya han sido cumplidas en el extranjero.

\section{X.2. Publicación de la Decisión Marco 3008/675/JAI}

Esta Decisión Marco (en adelante DM) establece el principio de equivalencia entre las condenas de otro Estado miembro de la UE y las propias, cuando estas tuvieran algún efecto o fueran consideradas en un nuevo proceso penal ${ }^{15}$. Además, dicho principio se aplicará, conforme a lo dispuesto en el art. 3.2 DM, en la fase previa al proceso penal, durante el propio proceso y en la fase de ejecución de la condena, en particular por lo que respecta a las normas de procedimiento aplicables, incluidas las relativas a la detención provisional, la calificación de la infracción, el tipo y el nivel de la pena impuesta, e incluso las normas que rigen la ejecución de la resolución. A expensas de la ulterior concreción en la incorporación legislativa que finalmente fuera objeto de aprobación, que debía realizarse a más tardar el I5.08.20I0, sus consecuencias resultaban potencialmente ponderables en nuestro ordenamiento para delimitar el problema de la eficacia de las condenas a efectos de

93 STS, Sala 2a , de I7.04.2013 (ROJ: STS 2477/2013; MP: Juan Saavedra Ruiz).

94 Instrumento de Ratificación del Convenio sobre traslado de personas condenadas, hecho en Estrasburgo el 21.03.1983 (BOE núm. I38, de I0.06.1985).

95 Conforme a lo dispuesto en su art. 3.I «Cada Estado miembro garantizará que se tomen en consideración, con motivo de un proceso penal contra una persona, las condenas anteriores pronunciadas en otros Estados miembros contra la misma persona por hechos diferentes, sobre las cuales se haya obtenido información a través de los instrumentos de asistencia judicial aplicables o mediante el intercambio de información extraída de los registros de antecedentes penales, en la medida en que se tomen en consideración las condenas nacionales anteriores y se atribuyan a aquellas condenas los mismos efectos jurídicos que a las condenas nacionales anteriores, de conformidad con el Derecho nacional». 
acumulación. En este ínterin, el $\mathrm{TS}^{96}$ acepta la posibilidad de la acumulación de una condena impuesta en Francia, que había sido denegada por la Audiencia Nacional, entre otras razones, porque al tratarse de hechos ocurridos en Francia y España no pudieron ser objeto del mismo proceso al ocurrir en territorios nacionales distintos, sometidos a la soberanía de diferentes países ${ }^{97}$. El TS, negando que constituya un límite a la posibilidad de acumulación el que la sentencia haya sido dictada por un tribunal de otro Estado de la UE, y entendiendo que, conforme al objetivo señalado por la DM 2008/675/JAI, existe una obligación mínima para los Estados miembros al objeto de tener en cuenta las condenas pronunciadas por otros Estados miembro, concluye que en ausencia de normas que regulen expresamente la materia de una forma terminante, la interpretación de las vigentes debería realizarse de la manera más conforme posible con el contenido de una normativa europea, cuya incorporación al ordenamiento interno es una obligación contraída por el Estado español como miembro de la UE.

La jurisprudencia del Tribunal de Justicia de la Unión Europea (en adelante TJUE), tras la doctrina Pupino ${ }^{8}$, obligaba a la denominada «interpretación conforme» de nuestro ordenamiento para lograr la finalidad prevista en la norma comunitaria, incluso en defecto de ley - praeter legem-. En este caso, la consecución de la asimilación de las condenas de otros Estados miembros a las condenas nacionales cuando tuvieran eficacia en un nuevo proceso. En consecuencia, corresponde al juez nacional verificar si, en el asunto concreto, es posible una interpretación conforme de su Derecho nacional. Por ello, el TJUE concluye que el órgano jurisdiccional nacional está obligado a tomar en consideración todas las normas del Derecho nacional y a interpretarlas, en todo lo posible, a la luz de la letra y de la

$9^{6}$ STS, Sala 2a ${ }^{a}$, de I3.03.20I4 (ROJ: STS 840/20I4; MP: Miguel Colmenero Menéndez de Luarca). Sobre las consecuencias y efectos de esta sentencia, Nistal Burón, J. / Ayuso Fernández, A. B., «La posibilidad de acumular condenas impuestas por tribunales extranjeros con las impuestas en España», en Diario La Ley, núm. 8307, de 9.05.2014, págs. 7 a 9.

97 Esta era la solución por la que anteriormente había optado la STS, Sala 2ª de I8.I2.2002, cit.

$9^{8}$ La STJUE, Gran Sala, de I6.06.2005 (Asunto C-I05/03, Pupino; MP: J.N. Cunha Rodrigues), en síntesis, desarrollaba su doctrina sobre la «interpretación conforme» de la siguiente manera: El carácter vinculante de las decisiones marco, formulado en términos idénticos a los del art. 249 CE, párrafo tercero, supone para las autoridades nacionales y, en particular, para los órganos jurisdiccionales nacionales, la obligación de interpretación conforme del Derecho nacional. Ha de reconocerse a los particulares el derecho a invocar las decisiones marco a fin de obtener una interpretación conforme del Derecho nacional ante los órganos jurisdiccionales de los Estados miembros. El principio de interpretación conforme se impone respecto de las decisiones marco, por lo que al aplicar el Derecho nacional, el órgano jurisdiccional remitente que debe interpretarlo está obligado a hacer todo lo posible, a la luz de la letra y de la finalidad de la DM, para, al efectuar dicha interpretación, alcanzar el resultado a que se refiere la DM y de esta forma atenerse al art. 34 UE, apartado 2, letra b). Sin embargo, la obligación del juez nacional tiene límites, que son: En primer lugar, los límites impuestos por los principios generales del Derecho y, en particular, en los de seguridad jurídica y no retroactividad. Dichos principios se oponen, concretamente, a que la referida obligación pueda tener por efecto determinar o agravar, basándose en la DM y con independencia de una ley adoptada para la ejecución de ésta, la responsabilidad penal de quienes infrinjan sus disposiciones. Y en segundo lugar, la obligación del juez nacional de tener presente el contenido de una DM en la interpretación de las correspondientes normas de su Derecho nacional cesa cuando éste no puede ser objeto de una aplicación que lleve a un resultado compatible con el que pretende alcanzar dicha DM. En otros términos, el principio de interpretación conforme no puede servir de base para una interpretación contra legem del Derecho nacional. Sin embargo, dicho principio requiere que el órgano jurisdiccional nacional tome en consideración, en su caso, todo el Derecho nacional para apreciar en qué medida puede éste ser objeto de una aplicación que no lleve a un resultado contrario al perseguido por la DM. 
finalidad de la DM. Estas consideraciones no sólo se predican de las decisiones marco, sino también de las Directivas ${ }^{99}$. En definitiva, a la luz de la DM 2008/675/JAI, ha de admitirse la posibilidad de acumular una sentencia de un Estado de la UE en una ejecutoria española siempre que los datos que puedan ser obtenidos permitan esta interpretación praeter legem.

\section{X.3. Publicación de la LO 7/20I4}

La LO 7/20I4 ${ }^{\text {I00 }}$ incorpora al derecho español la referida DM 2008/675/JAI, pero en el texto definitivo, al contrario que en la redacción contenida en el Anteproyecto y en el Proyecto legislativo, determinadas excepciones facultativas que contemplaba el art. 5.3 DM al principio de equivalencia entre las sentencias de otro Estado miembro y las propias, con motivo de un nuevo proceso penal, las incorpora al derecho interno. Se establecen así dos excepciones al principio de equivalencia de las sentencias condenatorias recaídas en otros Estados de la UE ${ }^{\text {Ior. }}$.

La primera de estas excepciones aparece definida en su art. I4.2, , conforme al cual las condenas firmes dictadas en otros Estados miembros no tendrán ningún efecto, de un lado, sobre las sentencias de condena que se impongan en procesos posteriores seguidos en España por delitos cometidos antes de que se hubiera dictado sentencia de condena por los Tribunales del otro Estado miembro; y de otro, sobre los autos dictados o que deban dictarse, conforme al párrafo tercero del art. 988 LECRIM, que fijen los límites de cumplimiento de penas entre las que se incluya alguna de las condenas a que se refiere el anterior supuesto. Es decir, se excepcionan de la acumulación jurídica las sentencias dictadas en procesos posteriores seguidos en España por delitos cometidos antes de que se hubiera dictado sentencia condenatoria por otro Estado miembro. La excepción de este art. I4.2, trataría de evitar que un sujeto que en un país de la Unión Europea haya extinguido penas por delitos cometidos y juzgados con posterioridad a los cometidos previamente en España, que alcancen, el máximo previsto en la normativa española (triplo de la más grave,

99 El principio de «interpretación conforme» se formuló por el TJUE en relación con las Directivas, ya en la STJUE de I0.04.I984 (Asunto I4/83, Von Colson y Kamann). Como aplicación más reciente, contamos con la STJUE, Gran Sala, de 4.04.2006 (Asunto C-2I2/04, Adeneler y otros; MP: R. Schintgen), en la que se indica que la obligación del juez nacional de utilizar como referencia el contenido de una Directiva, cuando interpreta y aplica las normas pertinentes de su Derecho nacional, tiene sus límites en los principios generales del Derecho, en particular en los de seguridad jurídica e irretroactividad, y no puede servir de base para una interpretación contra legem del Derecho nacional; que esta obligación general nace únicamente a partir de la expiración del plazo de adaptación del Derecho interno a dicha directiva; y que durante el plazo de adaptación del Derecho interno a una Directiva, los Estados miembros destinatarios de la misma deben abstenerse de adoptar disposiciones que puedan comprometer gravemente el resultado prescrito por ésta.

Iо० LO 7/20I4, de I2 de noviembre, sobre intercambio de información de antecedentes penales y consideración de resoluciones judiciales penales en la UE (BOE núm. 275, de I3.II.20I4), que procedía a la transposición de la DM 2008/675/JAI del Consejo, de 24.07.2008, relativa a la consideración de las resoluciones condenatorias entre los Estados miembros de la UE con motivo de un nuevo proceso penal (DOUE L 220, de I5.8.2008), con entrada en vigor al día siguiente de su publicación.

Ior Sobre las consecuencias y efectos en el ámbito de la ejecución penal de estas excepciones, NiSTAL BURÓN, J., «Excepciones de la ley española al principio de equivalencia de condenas de otros Estados miembros de la Unión Europea. Consecuencias y efectos en el ámbito de la ejecución penal», en Diario La Ley, núm. 8599, de 7.09.2015, págs. 8-10. 
20, 25, 30 o 40 años), cuando tenga que ser juzgado en España por los delitos cometidos aquí, antes de haber sido sentenciado por los delitos cometidos en el país extranjero, no se le pueda imponer pena alguna en España, ya que las ya cumplidas en el otro país cubrirían, hasta el límite de cumplimiento, las posibles condenas españolas.

La segunda de las excepciones, se contiene en la Disposición adicional única LO 7/20I4, cuando establece, con carácter general, que en ningún caso serán tenidas en cuenta para la aplicación de la presente Ley las condenas dictadas por un Tribunal de un Estado miembro de la UE con anterioridad al I5.08.20I0. Esta limitación temporal está fijada desde la citada fecha por ser la misma el momento límite para que España hubiera transpuesto la DM 2008/676/JAI.

Conforme a estas excepciones que establece la LO 7/20I4, la norma interna española no reconoce efectos a cualquier condena foránea de manera ilimitada, antes al contrario, limita los supuestos de condenas en el extranjero con efectos en España de dos maneras: atendiendo a criterios objetivos -art. I4.2-, y atendiendo a un criterio temporal imperativo, la referencia a las condenas anteriores al I5.08.20I0.

Una vez en vigor esta LO la interpretación conforme a la DM 2008/675/JAI ya no es posible, pues constituiría una interpretación contra legem del Derecho nacional ${ }^{102}$, límite infranqueable conforme a la propia jurisprudencia del $\mathrm{TJUE}^{\mathrm{IO}}$. Con anterioridad a la vigencia de esta LO no existía norma interna que determinara la exclusión de la

Iо2 A esta interpretación obedece la citada STS, Sala $2^{\text {a }}$, de 27.0I.20I5, cuyo criterio ha sido reiterado en numerosas sentencias posteriores: SSTS, Sala $2^{\mathrm{a}}$, de 24.03.20I5 (ROJ: STS I238/20I5; MP: Andrés Palomo del Arco); 24.03.20I5 (ROJ: STS I239/20I5; MP: Andrés Palomo del Arco); 20.04.20I5 (ROJ: STS I905/2015; MP: José Ramón Soriano Soriano); 7.05.20I5 (ROJ: STS 2I78/2015; MP: José Ramón Soriano Soriano); 24.05.2015 (ROJ: STS 2723/20I5; MP: Julián Artemio Sánchez Melgar); 27.09.20I5 (ROJ: STS 424I/20I5; Alberto Gumersindo Jorge Barreiro); I8.II.20I5 (ROJ: STS 5455/20I5; MP: Antonio del Moral García); 7.I2.20I5 (ROJ: STS 5523/2015; MP: Antonio del Moral García); 26.05.20I6 (ROJ: STS 2359/2016; MP: Juan Ramón Berdugo Gómez de la Torre); y 20.04.20I6 (ROJ: STS I704/20I6; MP: Antonio del Moral García). Esta STS de 27.I.20I5 indicaba que la interpretación conforme a la DM 2008/675/JAI, ya no era posible, pues integraba en el momento del dictado de esa resolución una interpretación contra legem del Derecho nacional, límite infranqueable conforme a la propia jurisprudencia del TJUE. No se trata de aplicación directa de la LO 7/2OI4, sino la constatación de su existencia, como obstáculo o circunstancia fáctica impeditiva para interpretar la normativa española, art. 76.2 CP (antes 70.2 CP 1973) y 988 LECRIM, para poder fijar el límite del cumplimiento de las penas impuestas en caso de plurales infracciones impuestas en diversos procesos cuando hubieran podido enjuiciarse en uno solo, si alguna de las condenas hubiera sido impuesta por otro Estado miembro de la UE, de manera tendente al logro de la finalidad genérica prevista en la DM 2008/675/JAI, sin atender a la facultad de no exigencia en los supuestos del propio art. 5.3 de la Decisión, en cuanto dicha facultad de inexigibilidad posibilitada por la propia Decisión, había sido acogida en su incorporación a derecho interno. Es decir, cuando se dicta la STS de I3.03.20I4, no existía norma interna que determinara la exclusión de la acumulación de condenas para la sentencias dictadas por otro Estado miembro; de modo que la interpretación obligada, praeter legem era la aplicación del principio de equivalencia entre las sentencias propias y las de otro Estado miembro con motivo de un nuevo proceso penal, que establecía la DM 2008/675/JAI, pues si bien, en dicha Decisión se contemplaban determinadas excepciones o no exigencia de observar este principio de equivalencia o asimilación, donde alguna de ellas, posibilitaba excluir determinadas acumulaciones, en cuanto excepciones meramente potestativas, la restricción interpretativa de su ámbito se imponía. Señala la STS de 24.03.20I5, cit., que «no se trata de la aplicación de esta nueva LO, sino exclusivamente de la diversa interpretación que de los artículos 76.2 CP y 988 LECRIM resulta viable desde la perspectiva de la DM 2008/675/JAI; como toda interpretación, tiene su anclaje cronológico en el momento de dictarse la resolución. La circunstancia de que el resultado fuere el mismo que si la LO 7/20I4 se aplicara directamente, no debe obscurecer el entendimiento del método y operación realizada, que deriva exclusivamente de la inviabilidad de mantener ahora una interpretación que sería contra legem».

I03 A esta interpretación obedece la citada STS de 27.0I.20I5, cit. 
acumulación de condenas para la sentencias dictadas por otro Estado miembro, de modo que la interpretación obligada, praeter legem, era la aplicación del principio de equivalencia entre las sentencias propias y las de otro Estado miembro con motivo de un nuevo proceso penal, que establecía la DM 2008/675/JAI.

Tras la entrada en vigor de esta LO no se puede mantener el argumento de que la DM es una norma más favorable, porque tal instrumento jurídico no tiene efecto directo, como resulta pacífico en esta materia ${ }^{104}$. Las Decisiones Marco tienen un valor interpretativo mientras no son transpuestas, pero nunca un valor vinculante para los Tribunales. Por ello no cabe hablar en sentido estricto de un sistema de fuentes de derecho ni de una jerarquía normativa ${ }^{105}$. Desde una visión material del principio de legalidad penal no resulta compatible una DM con las exigencias de certeza, determinación y taxatividad que las normas penales requieren, siendo preciso que las disposiciones de una DM sean transpuestas a los textos legales que integran el derecho penal interno del Estado miembro, única forma de que obliguen directamente al ciudadano y pueda ajustar su conducta a los mandatos de unas normas que afectan de una forma muy directa y gravosa a sus derechos fundamentales. Las decisiones marco se utilizan para aproximar las disposiciones legislativas y reglamentarias de los Estados miembros, obligando a dichos Estados -no a los ciudadanos ni a los Tribunales-, a obtener los resultados unificadores pretendidos, pero dejando a las instancias nacionales la decisión sobre la forma y los instrumentos necesarios para alcanzarlos. La jurisprudencia del TJUE se ha mostrado contraria a la aplicación directa de las normas comunitarias en el ámbito de la jurisdicción penal de los Estados miembros $^{\text {I06 }}$. La DM es un instrumento que permite que los Estados miembros de la Unión armonicen sus legislaciones, pero no armoniza o reunifica directamente por sí misma tales legislaciones, careciendo de efecto directo. Lo que sí imponen es interpretar la legislación nacional conforme a los objetivos de la DM, pero con el límite de que no es posible una interpretación contra legem, y en nuestro caso nunca podían haberse enjuiciado estos delitos en el mismo proceso, ante la inexistencia de marcos comunitarios que permitan juzgar en un Estado los delitos cometidos y sentenciados en otro distinto.

\section{Conclusiones}

I. La norma reguladora de esta materia establece el límite máximo de cumplimiento efectivo de la condena impuesta, en la misma sentencia, al culpable de varias infracciones penales, en el triple del tiempo de la más grave de las penas que se le hubieren aplicado, sin que su duración pueda tampoco exceder los veinte años, salvo las excepciones que en la actualidad se establecen para la superación de este límite máximo. Se admite, incluso, la aplicación de semejante régimen de acumulación de penas a las que se impusieren en

I04 Así lo asumen los votos particulares firmados frente a la STS, Sala $2^{\mathrm{a}}$, de 27.01.2015, cit.

ro5 STS, Sala $2^{\mathrm{a}}$, de I2.I2.20II (ROJ: STS 8470/20II; MP: Alberto Gumersindo Jorge Barreiro).

ro6 Así, la STJUE, Sala 6a , de 8.Io.I987 (Asunto 80/86, Kolpinghuis Nijmegen) declaró que «una Directiva no puede por sí sola y con independencia de una ley interna promulgada para su aplicación, determinar o agravar la responsabilidad penal de quienes la contravengan». 
procedimientos distintos, con la única exigencia de que los hechos a que las mismas se refieran, por la conexión existente entre ellos, hubieren podido enjuiciarse en un solo procedimiento. Tal previsión legal tiene como principal fundamento normativo, el de posibilitar eficazmente el sentido reeducador y reinsertador de la sanción penal al que, de modo concreto para la pena privativa de libertad, se refiere el art. 25.2 CE, dentro de un marco de inspiración humanitaria del sistema penal, al considerar esos plazos máximos de cumplimiento período suficiente para alcanzar el referido objetivo resocializador que, de otra forma, podría verse frustrado al carecer de sentido y estímulo para el propio penado, en el caso de que su sometimiento al cumplimiento de las sanciones impuestas no tuviere fin o fuere éste tan dilatado en el tiempo que hiciera inútil.

En base a estas razones de principio y superando un antiguo criterio que ponía el acento en la concurrencia de la conexidad de los hechos que motivaron la aplicación de las penas cuya refundición se solicitaba en los términos en los que dicha conexidad es contemplada en el art. I7 LECRIM, el TS en la actualidad atiende tan sólo a un criterio estrictamente temporal, es decir, tan sólo referido al dato esencial de que, en definitiva, los delitos hubieren podido ser realmente enjuiciados en un mismo procedimiento, a la vista de las diferentes fechas de acaecimiento y posterior enjuiciamiento de los mismos. Semejante solución de restringir las posibilidades de la acumulación al menos al dato cronológico de la posibilidad teórica de enjuiciamiento conjunto de los diferentes hechos sancionados, se asienta no sólo en la propia exigencia expresa contenida en el art. $76 \mathrm{CP}$, sino también en el hecho evidente de que, de no hacerse así, siempre serían posibles sucesivas acumulaciones de condenas a otras precedentes, prolongándose la acumulación ad infinitum, de modo que quien ya hubiere alcanzado la primera de ellas dispondría de la impunidad de sus ulteriores conductas infractoras, cuyo castigo quedaría englobado en aquella, sin repercusión alguna, especialmente cuando la pena ulteriormente impuesta fuere igual o inferior a la que ya sirvió de base para fijar el límite del resultado de la acumulación. Y más aún, si se hubiera alcanzado el límite máximo de los veinte, treinta o, en la actualidad, incluso cuarenta años, en cuyo caso, cualquier delito posterior, por grave que fuere, carecería de toda repercusión sancionadora, anulándose así los fines de prevención propios de la norma penal.

En este sentido, el criterio actual es incuestionablemente generoso, pero también suficientemente claro al impedir la inclusión en una determinada acumulación de las penas impuestas por hechos cometidos con posterioridad a la primera de las sentencias que dicha acumulación abarca, pues en tal caso, evidentemente, puede afirmarse que resultaría del todo imposible que tales nuevos hechos, posteriores a aquella, hubieran podido ser enjuiciados en ese mismo procedimiento ya finalizado cuando acaecen. Por el contrario, la acumulación se ve siempre como posible, sin exigencia de otro requisito, para la totalidad de los delitos que se hubieren cometido antes de recaer esa primera sentencia o, por mejor decir, antes de la primera fecha de entre las sentencias recaídas.

2. En cuanto a la fecha de condena a la que hay que atender es la correspondiente a la sentencia y no a su firmeza. No cabe la acumulación con condenas por hechos cuya fecha de comisión sea posterior a la fecha de la sentencia a refundir, aunque anterior a su 
firmeza. En este sentido el Pleno de la Sala de lo Penal del TS de 29.II.2005 declaró que «no es necesaria la firmeza de las sentencias para el límite de la acumulación». Una vez sentenciados unos hechos, aunque esté pendiente un recurso, no es posible el enjuiciamiento conjunto con causas seguidas por hechos posteriores y por tanto nunca puede hablarse de hechos que podrían haberse enjuiciado conjuntamente. El fundamento de ese límite temporal -evitar la conciencia de impunidad por los delitos sucesivostambién aparece en estos supuestos. De admitirse otra tesis llevando el límite a la fecha de la firmeza se privilegiaría a quien interpone un recurso, aunque sea infundado, para desplazar esa fecha en el tiempo, frente a quien acata la sentencia. Deben, pues, entenderse como épocas diferentes no acumulables las que se encuentren separadas por la existencia de alguna sentencia condenatoria aunque no sea firme. No existe en nuestro sistema un derecho fundamental a la impunidad de los delitos cometidos cuando ya ha sido fijado un límite máximo de cumplimiento como consecuencia de la acumulación de condenas practicada.

3. La sentencia que determina la acumulación es la de fecha más antigua. Tomando como referencia esta sentencia, serán susceptibles de acumulación las penas impuestas por hechos que, enjuiciados en otras causas, sean de fecha anterior a tal sentencia. Hecha esta primera comprobación, habrá de calcularse si los límites relativos o absolutos del art. $76 \mathrm{CP}$ son más beneficiosos que la suma aritmética de las penas impuestas, en cuyo caso procederá la acumulación. Para determinar la pena de mayor gravedad a estos efectos, ha de atenderse a las penas individualmente impuestas en cada sentencia, sin que sea admisible la suma de las impuestas en una misma sentencia por delitos diferentes, para atribuir a esta suma la condición de pena más grave.

4. Denegada una acumulación de condenas, no podrá replantearse una y otra vez cuando se agotaron los recursos procedentes. Si llega otra condena lo antes decidido será intangible. Tan solo cabrá considerar si esa nueva condena altera los términos en que se hizo la acumulación, lo que puede suceder. Pero no cabrá alterar la anterior decisión si para nada incide en ella la condena que se conoce después.

5. Los mecanismos de limitación de cumplimiento de condenas no dan vida a una nueva pena distinta de las anteriores. Todas las penas impuestas subsisten y se van cumpliendo sucesivamente. Las fórmulas reductivas -como el abono de prisión preventiva-, no operan respecto del total de cumplimiento preestablecido, sino en relación a cada una de las penas que sucesivamente se van dejando extinguidas. El máximo de cumplimiento juega como un tope y no crea una nueva pena. Eso significa, dicho más simplemente, que para establecer el máximo de cumplimiento no han de descontarse los periodos en que la prisión preventiva haya estado simultaneada con el cumplimiento de una pena de prisión en ejecución. El concepto de cumplimiento efectivo tiene un significado material -estancia efectiva-, que no se compadece ni bien ni mal con considerar que quien estaba en prisión como preventivo y como penado estaba dos veces en prisión. Eso no es doble cumplimiento efectivo. De ahí que en estos casos el abono de esa prisión preventiva padecida cuando se estaba cumpliendo otra pena, se hará para reducir el cumplimiento de la condena que recayó en esa causa, pero no para descontarlo del máximo de cumplimiento 
fijado. Las penas solo quedarán extinguidas cuando se llegue al máximo temporal de cumplimiento. Pero para contar ese máximo no se tiene en cuenta más que el tiempo efectivo de estancia en prisión y no la ficción del doble cómputo. El máximo no es una nueva pena diferente de las anteriores. Son las mismas enlazadas y sucesivamente cumplidas con un total de estancia en prisión o, en libertad condicional, que también es cumplimiento.

6. Las SSTS, con alguna excepción, admitían la acumulación de sentencias foráneas y nacionales cuando se trataba de la acumulación de condenas impuestas en España con condenas todavía no cumplidas e impuestas en el extranjero, cuando un Convenio internacional determinaba su ejecución en España y con sometimiento a la normativa española. El art. 76.2 CP (anterior 70. $2^{\text {a }}$ CP I973) y el art. 988 LECRIM no consentían sin el complemento de un Convenio desplegar sus efectos sobre estas ejecutorias foráneas. Por el contrario, cuando esas condenas impuestas en el extranjero ya habían sido cumplidas en el respectivo país, la acumulación es denegada. No existe Acuerdo o Convenio Internacional que posibilite la aplicación de las normas españolas sobre imposición de penas derivadas de plurales infracciones, cuando una es española y otra extranjera si la ejecución de ambas no está sometida a nuestra jurisdicción.

La DM 3008/675/JAI se aprobó para encumbrar un principio de equivalencia entre las condenas de los Estados miembros, cuando estas pueden tener algún efecto en un nuevo proceso penal. Este principio se aplicará en la fase previa al proceso penal, durante el propio proceso y en la fase de ejecución de la condena, en particular por lo que respecta a las normas de procedimiento aplicables, incluidas las relativas a la detención provisional, la calificación de la infracción, el tipo y el nivel de la pena impuesta, e incluso las normas que rigen la ejecución de la resolución. La DM debía incorporarse a los ordenamientos internos antes del I5.08.20IO. Pendiente su implementación, la STS de I3.03.20I4 tomando como referencia la DM y usando como criterio exegético el principio de interpretación conforme rompió con el precedente existente. Sin embargo, el principio de interpretación conforme no puede estirarse hasta avalar una interpretación contra legem del Derecho nacional. La LO 7/20I4 incorporó al derecho español la referida DM, pero en su texto definitivo determinadas excepciones contempladas como facultativas en la DM son asumidas por el Derecho interno. Específicamente se alude a los autos previstos en el art. 988 LECRIM que fijan los límites de cumplimiento de las penas en las que se incluya alguna condena impuesta en procesos posteriores seguidos en España por delitos cometidos antes de que se hubiera dictado sentencia de condena por los Tribunales de otro Estado miembro; y de manera genérica, a las condenas dictadas por otro Estado miembro de la Unión europea con anterioridad al I5.08.20I0.

7. Una aplicación rígida y cerrada de nuestro sistema de acumulación jurídica, sin prever distintas posibilidades combinatorias, arrojaría unos resultados contrarios a cualquier principio retributivo y proporcional de la pena como sería que una multiplicidad de delitos menores contra la propiedad fuesen castigados a la postre más severamente que delitos mucho más graves contra la vida o integridad de las personas. El enjuiciamiento de los hechos pende en muchas ocasiones de circunstancias o contingencias aleatorias y por 
ello ajenas a la responsabilidad de los propios penados y que incluso pueden conculcar el principio de igualdad en la aplicación de la ley. Ello no puede corregirse absolutamente pero cuanto más flexible sea la posibilidad combinatoria se reducirá el margen de aleatoriedad. La aplicación de la norma requiere previamente su interpretación, lo que también sucede en ocasiones con la jurisprudencia en todos aquellos casos en los que no es posible la identificación absoluta del sentido de la norma -o de la jurisprudencia en su caso- a través exclusivamente de su literalidad, de ahí la complejidad de la función interpretativa (art. 3.I $\mathrm{CC})$.

XII. Bibliografía

Armenta González Palenzuela, F.J. / Rodríguez Ramírez, V., Reglamento penitenciario comentado: análisis sistemático y recopilación de legislación, MAD, Sevilla, 2004.

Ayo Fernández, M., Manual de determinación de las penas y de las demás consecuencias jurídicopenales del delito, Aranzadi, Pamplona, 1997.

Bérdugo Gómez De La Torrre, I. (Coord.) / De Vicente Martínez, R., et. al., Lecciones y materiales para el estudio del Derecho Penal, V. 2 (Teoría del delito), Iustel, Madrid, 2010.

Bujosa VAdell, LM., «Reconocimiento y ejecución de sentencias penales extranjeras» en Diario La Ley núm. 5350, de I2.07.200I.

Calderón Cerezo, A. / Choclán Montalvo, J. A., Derecho penal, Bosch, Barcelona, 200I.

Cervelló Donderis, V., Derecho penitenciario, Tirant lo Blanch, Valencia, 2006.

Conde-Pumpido Ferreiro, C., en López Barja De Quiroga, J. (Coord.) / Rodríguez Ramos, L / Álvarez García, J., et al., Código Penal Comentado, Akal, Madrid, I990.

Conde-Pumpido Ferreiro, M., «Art. 76», en Conde-Pumpido Ferreiro, M. (dir.), Código Penal comentado: con concordancias y jurisprudencia, Bosch, Barcelona, 2004.

Cuerda Riezu, A., «La regulación del concurso de delitos en el anteproyecto de Código Penal de i992», en Сово Del Rosal, M. / Ruiz Vadillo, E. et al., Política criminal y reforma penal: homenaje a la memoria del profesor Dr. D. Juan del Rosal, EDERSA, Madrid, I993.

Cuerda Riezu, A., Concurso de delitos y determinación de la pena: análisis legal, doctrinal y jurisprudencial, Tecnos, Madrid, I992.

Delgado García, J., «Refundición de condenas: la regla $2^{a}$ del art. 70 CP», en La Ley, núm. 4, I995.

Fernández Arévalo, L. / Nistal Burón, J., Manual de derecho penitenciario, Aranzadi, Navarra, $20 I I$.

FERNÁNDEZ PinÓs, J. E., «Acumulación de condenas y refundición de penas», en Estudios jurídicos, Cuerpo de Secretarios Judiciales, núm. 2, Ministerio de Justicia, Madrid, 2000.

Ferrer Gutiérrez, A., Manual práctico sobre ejecución penal y derecho penitenciario, Tirant lo Blach, Valencia, 20II.

GonZÁlez Rus, J. J., «Artículos 73 y 75 al 78», en Совo Del Rosal (Coord), et al., Comentarios al CP, Edersa, Madrid, I999.

Lamo Rubio, J., Penas y Medidas de Seguridad en el nuevo Código, Bosch, Barcelona, I997.

LlorCa ORTEGA, J., Manual de determinación de la pena: conforme al CP de 1995, Tirant lo Blanch, Valencia, I999.

López CerRadA, V. M., «La acumulación jurídica de penas», en Revista de Estudios Penitenciarios, núm. 250, 2004.

Manzano Moreno, E. C., La ejecución penal: estudio crítico legal y jurisprudencial sobre una materia relegada, Dykinson, Madrid, $20 \mathrm{I2}$. 
Mapelli Caffarena, B. / Terradillos Basoco, J., Las consecuencias jurídicas del delito, $3^{\mathrm{a}}$ ed., Civitas, Madrid, I996.

Maqueda Abreu, M. L, «El concurso de delitos», en Zugaldía Espinar, J. M (dir.), Derecho penal Parte general, Tirant lo Blanch, Valencia, 2002.

Martínez De la Concha Álvarez Delvayo, VIII Reunión de Jueces de Vigilancia Penitenciaria, CGPJ, Madrid, I996.

Mir Puig, S., Derecho Penal, Parte General, Reppertor, Barcelona, 2006, p. 645; SuÁrez GonZÁlEZ, C., «Artículo 76», en Rodríguez Mourullo, G. (dir.), Comentarios al Código Penal, Civitas, Madrid, I997.

MuÑoz Conde, F, «Hacia un derecho penal del enemigo?», en Diario el País, Madrid, I5.01.2003.

Muñoz Conde, F. / García ArÁn, M., Derecho penal Parte general, Derecho penal, Parte general, Tirant lo Blanch, Valencia, 2ого.

Nistal Burón, J. / AyUso FernándeZ, A. B., «La posibilidad de acumular condenas impuestas por tribunales extranjeros con las impuestas en España», en Diario La Ley, núm. 8307, de 9.05 .2014 .

Nistal BURÓN, J., «Excepciones de la ley española al principio de equivalencia de condenas de otros Estados miembros de la Unión Europea. Consecuencias y efectos en el ámbito de la ejecución penal», en Diario La Ley, núm. 8599, de 7.09.2015.

NISTAL BURÓN, J., «La interpretación jurisprudencial de la conexidad en el concurso real de delitos (art. 76.2 del CP). El sentido de la pena y la Ley penitenciaria como criterio de apreciación», en Revista de Derecho Penal, núm. 29, 20 Io.

Peiteado Mariscal, P., La ejecución jurisdiccional de las penas privativas de libertad, Edersa, 2000.

Quintero Olivares, G., Manual de derecho penal, Parte general, Aranzadi, Navarra, 2002.

RENART GARCíA, F., La libertad condicional: nuevo régimen jurídico (adaptada a la LO 7/2003, de 30 de junio, de medidas para el cumplimiento íntegro y efectivo de las penas), Edisofer, Madrid, 2003 .

Ríos MarTín, J. C., Manual práctico para la defensa de las personas presas, Colex, Madrid, I997.

Serrano Butragueño, I., Las penas en el nuevo C.P. L.O. IO/I995. Doctrina, Jurisprudencia, Derecho comparado y Casos prácticos, Comares, Granada, I996.

SuÁrez GonzÁlez, C., «Artículo 76», en Rodríguez Mourullo, G. (Dir.), Comentarios al Código Penal, Civitas, Madrid, I997.

SuÁRez-Mira Rodríguez, C. (coord.), Manual de Derecho penal, T. I, Thomson Civitas, Navarra, 2004 .

TÉllez AguilerA, A., «La Ley de cumplimiento íntegro y efectivo de las penas: Una nota de urgencia», en Diario La Ley núm. 5837, I4.08.2003. 